\title{
ROOTING THE ARCHITECTURAL VALUES OF HERITAGE IN THE CONTEMPORARY ARCHITECTURE (AN ANALYTICAL STUDY OF THE ARCHITECTURE HERITAGE AT AL-BAHA IN THE KINGDOM OF SAUDI ARABIA IN ORDER TO BE STABILIZED WITHIN THE CONTEMPORARY ARCHITECTURE)
}

\author{
Ali Saied Bokhary ${ }^{* 1}$ and Mahmoud Tarek Mohamed Hammad ${ }^{2}$ \\ ${ }^{1}$ Architecture Department, Faculty of Engineering, Al Baha University, Al Aqiq, Kingdom \\ of Saudi Arabia. \\ ${ }^{2}$ Architectural Engineering, Department, Al-Azhar university, Cairo, Egypt \\ *Corresponding Author E-mail: abokhari@ bu.edu.sa
}

\begin{abstract}
A rich cultural and urban heritage has been accumulated through successive ages and generations on the land of Kingdom of Saudi Arabia, especially in Al-Baha Area, whose features are still clear and its impacts are existing nowadays. Such heritage is reflecting the society's features, physical, environmental, and social merits, and as a result of the rapid changes in all aspects of life, architectural trends and ideas are emerged, which not much consistent with the values of society known with the civilization history. Hence, and to link the values of the past with the present, it is required to study the values of this local heritage and rooting it in the contemporary buildings by a deepen and balanced local vision matching with the present capacities and the past authenticity, so this study aims to draw out and study these values which including many systems of environmental treatments that could be rooted in contemporary architectural works that keep with age potentials and culture of the society. It also emphasized the continuity of Al Baha civilization identity, as well it provides and embodies certain architectural templates, which represent attempts of intellectual integration between heritage and contemporary in an attempt to create a sense of belonging and emphasize the architectural identity of Al Baha city. Furthermore, the study has adopted the analytical inductive methodology, progressive from the theoretical approach for studying the concepts related to heritage, contemporary, and their relevant concepts of values.
\end{abstract}

Then, the study adopted the empirical approach through analyzing the contemporary concepts and trends in Al Baha to analyzing the most significant characteristics and values of Al Baha heritage architecture. The research concludes in identifying the architectural values that could be rooted at Al Baha contemporary architecture, providing a proposal enables us to solve the dilemma of local urbanization and architecture, besides arising the functionality of construction for achieving the contemporary architectural identity to Al Baha City.

KEYWORDS : Cultural \& Urban Heritage, Values of Heritage, Present Potential, Rooting Values, Continuity, the Local Identity, Contemporary Architecture. 


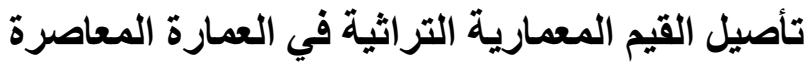

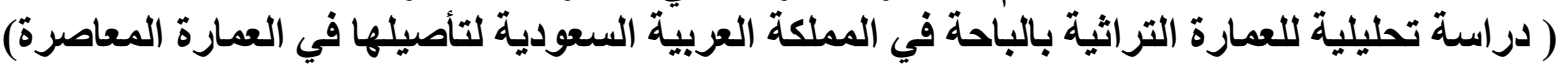

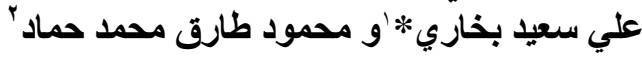

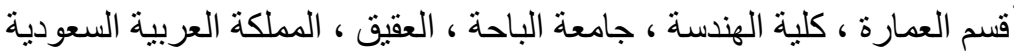

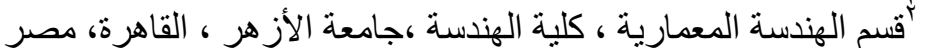

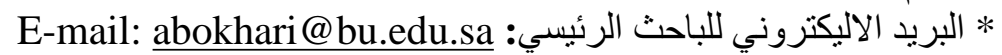

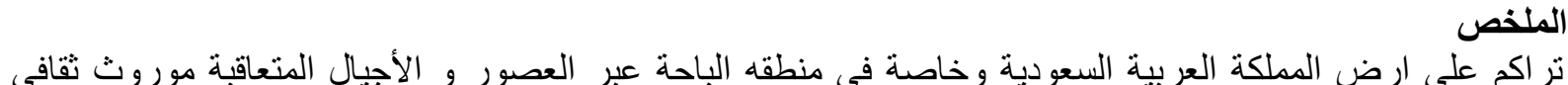

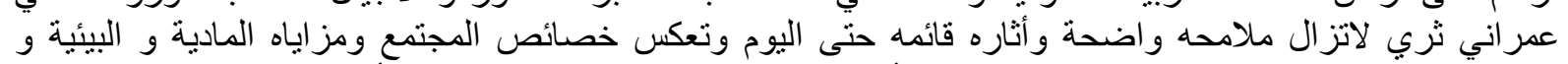

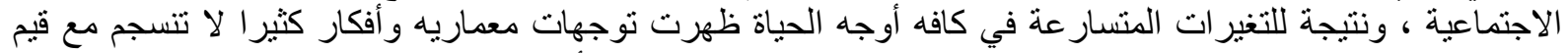

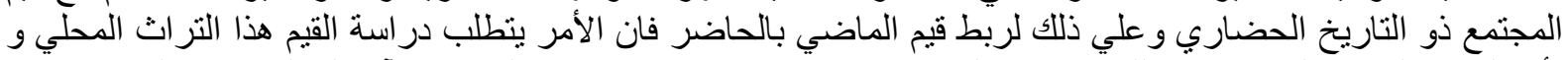

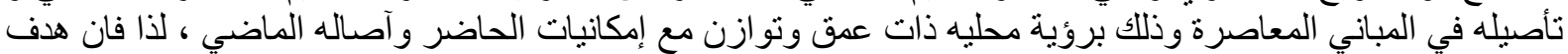

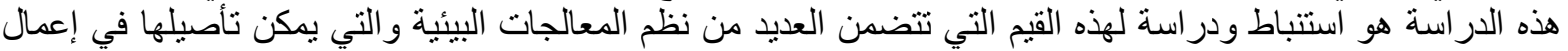

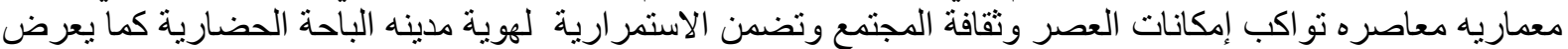

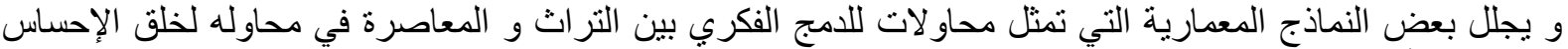

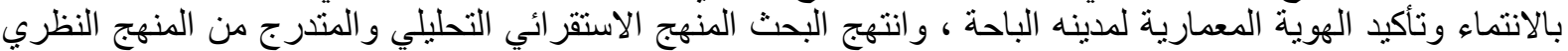

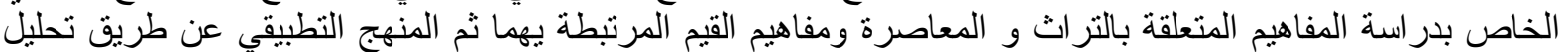

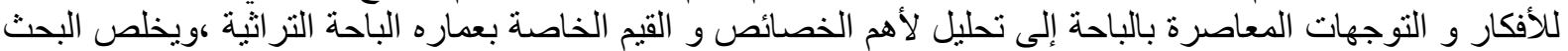

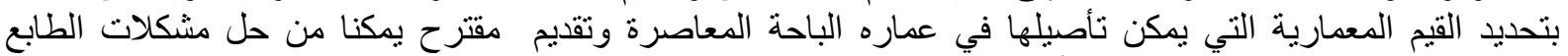

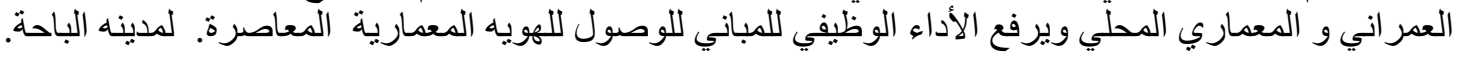

الكلمات المفتاحية : موروث ثقافي عمراني ، قيم التراث ، إمكانات الحاضر ، تأصيل القيم ، الاستمرارية ، الهوية

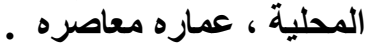

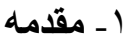

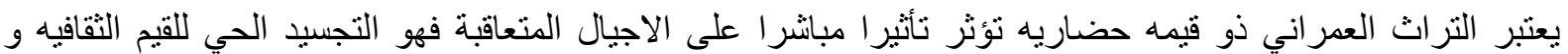

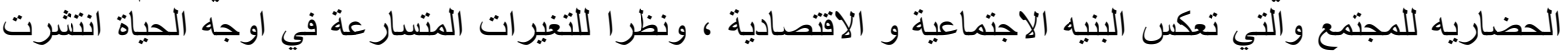

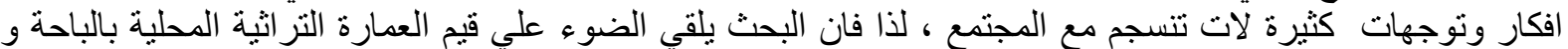

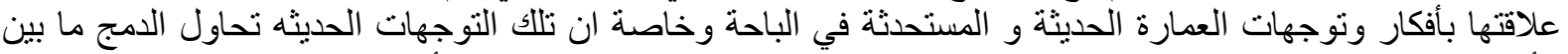

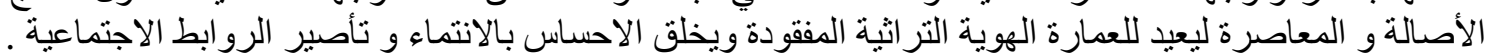

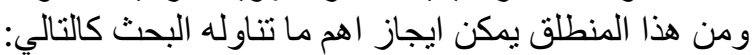

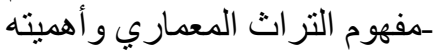

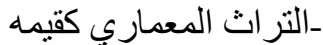

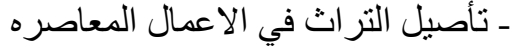
ـالقيم المعماريه التر اثيه المحليه ـانشكاليات تو اجه التراث التراثه المعماريه

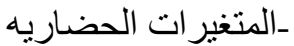

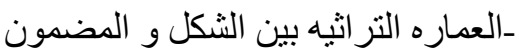
ـ الاتجاهات الفكرية بين التأصيل و التجديد التبديد

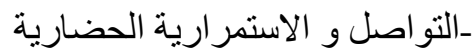

المشكله البحثيه البوني

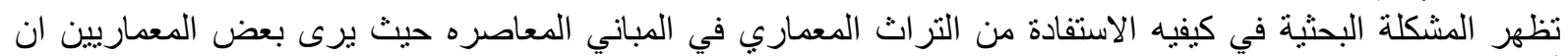

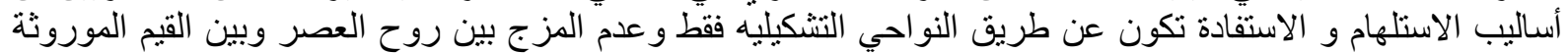
ودون معرفه البعد النتراثي التاريخي و هذا ما يسعي البحث الى تحقيقه كربط بين الفكر الذي ير الذي اعي القيم المعمارية التراثية

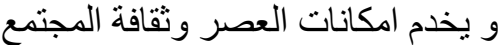
هاف البحث

ـ القاء الضوء على القيم المعماريه ومضمونها في عماره الباحة التراثية و اتي يمكن تأصيلها في عماره الباحة المعاصره 
ROOTING THE ARCHITECTURAL VALUES OF HERITAGE IN THE CONTEMPORARY ARCHITECTURE

ـ عرض وتقييم مجمو عهد من النماذج المعمارية المعاصرة في مدينه الباحة و التي تحاول الربط الفكري بين تراث الباحة

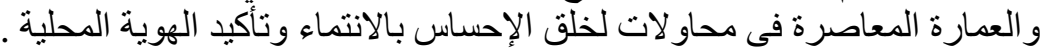

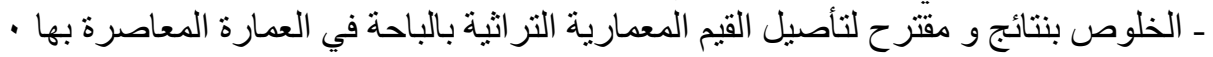

منهجيه الدراسة

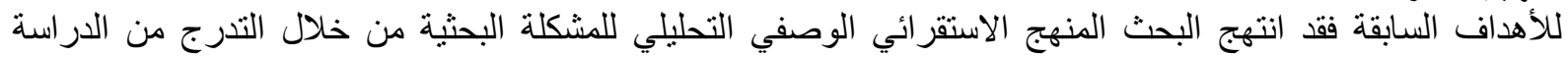

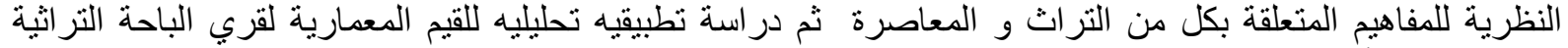
و التوجهات و الأفكار التي قام بها المعماريون في مشاريع معاصره بالباحة للمحافظة على هوية العمارة المحلية بها.

بـ بمفوم التزاث المعماري وأهميته

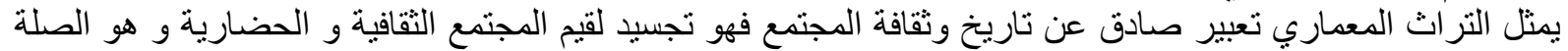

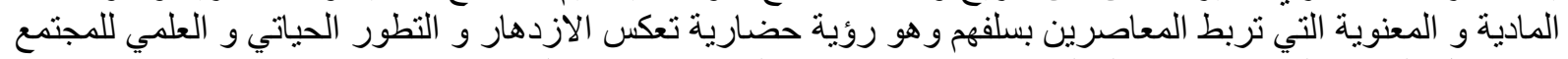

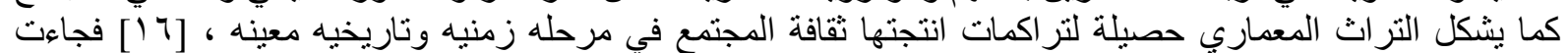

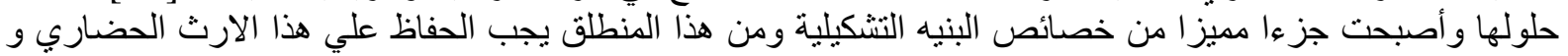

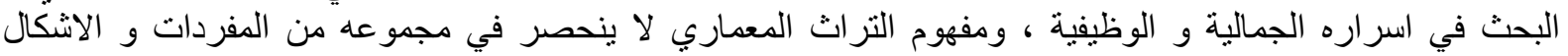

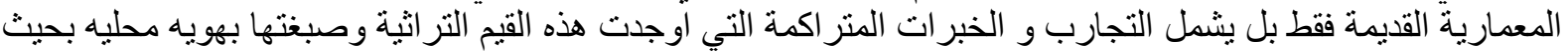

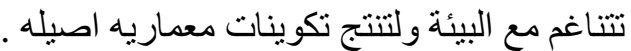

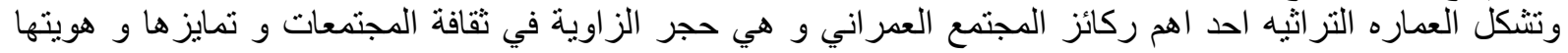

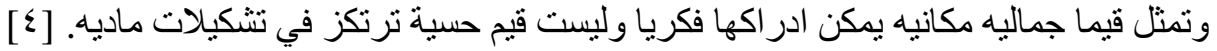

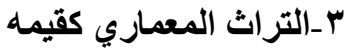

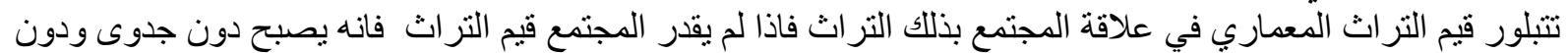

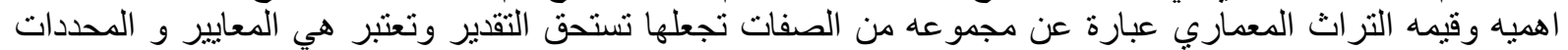

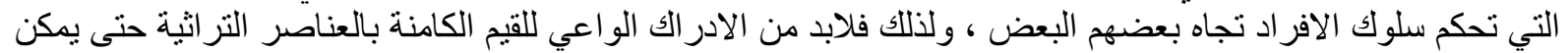

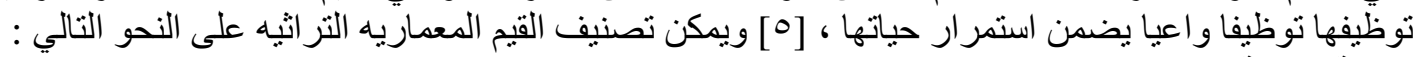

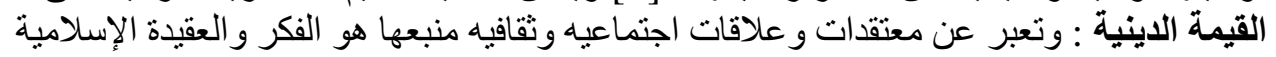

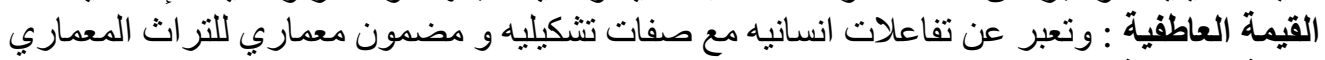

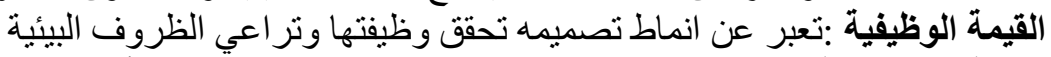

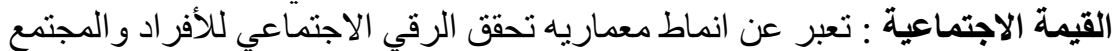

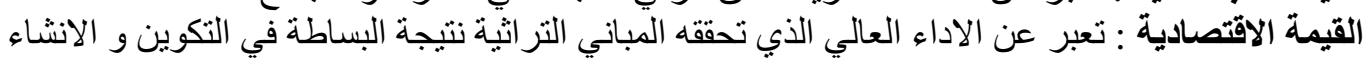

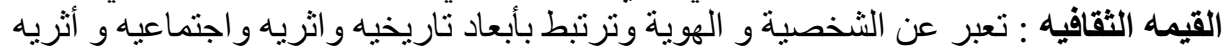

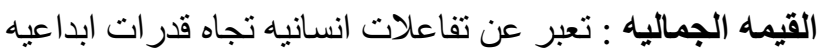

ـ ـ تأصيل التراث في الاعمال المعاصره

يرتبط الفكر المعماري دائما بروح المعاصئ المكان ومعطيات الزمان المان المتغيره و المعماري يتأثر بالعديد من المؤثرات الخارجية

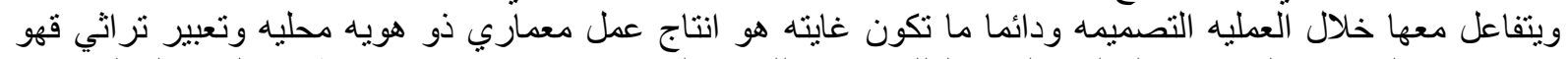

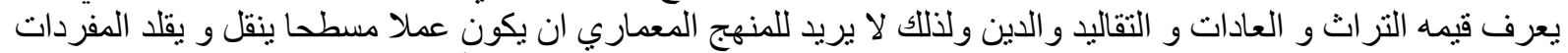

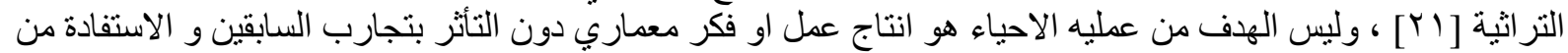

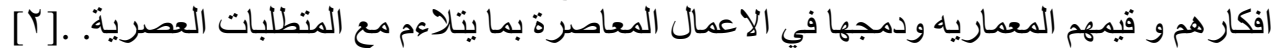

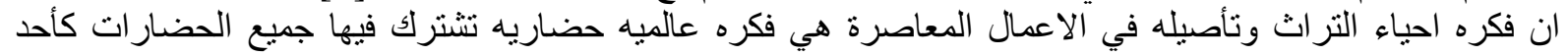

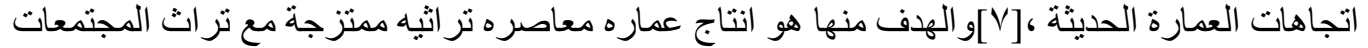

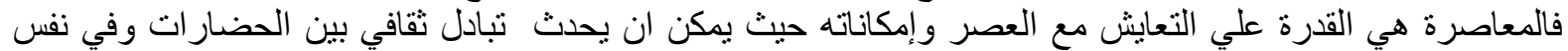

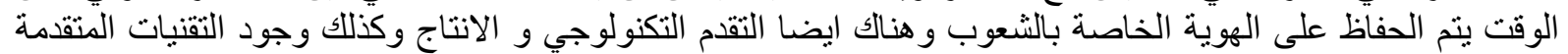

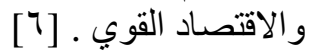

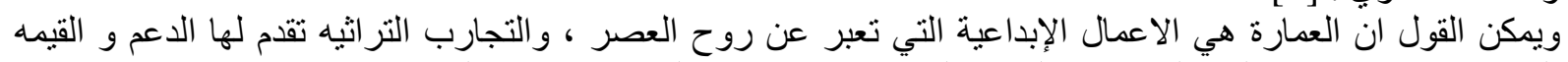

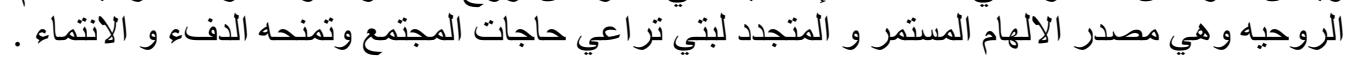

هـاشكاليات تواجه التراث المعماري يو اجه التراث المعماري العديد من اسباب تدهور المباري القيم الخاصة به من اهمها : ا ـ اسباب بشريه 
ROOTING THE ARCHITECTURAL VALUES OF HERITAGE IN THE CONTEMPORARY ARCHITECTURE

وترجع الي تراجع الاهتمام بالثقافة و التاريخ بسبب تراجع الانتاج الفكري الثقافي وكذلك عدم الاهتمام بالترويج لقيمه

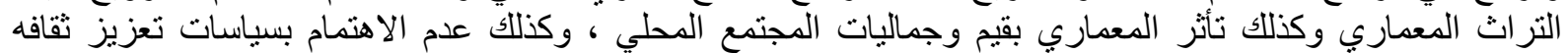

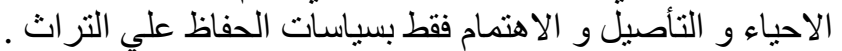
باسباب علميه

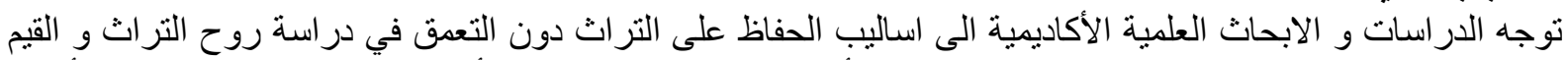

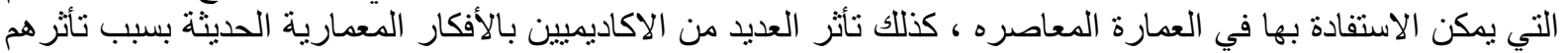

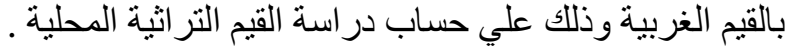
بـ اسباب تكنولوجيه

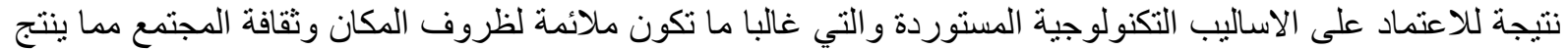

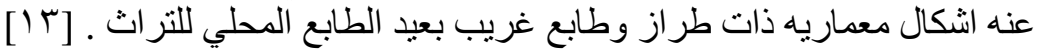

7-المتغيرات الحضارية اسفرت التغيرات السياسيه و الحضاريه مع تقدم التقنيه وظهور المعرفه العلميه المعاصره الي ظهور مدارس معثماريه

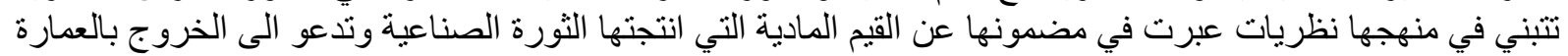

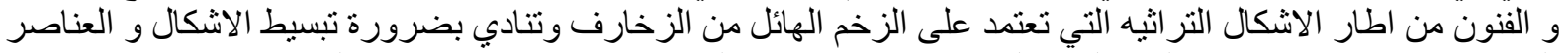

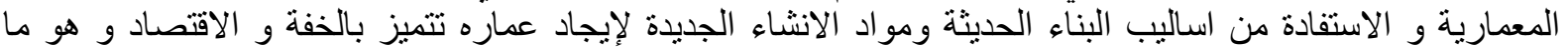

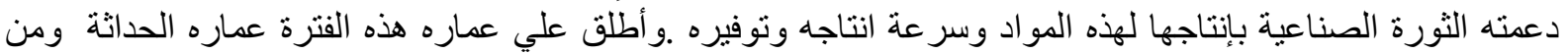

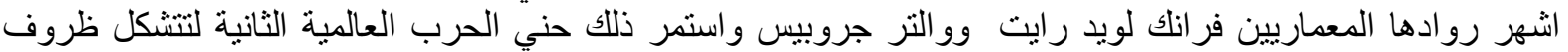

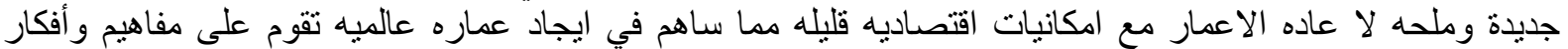

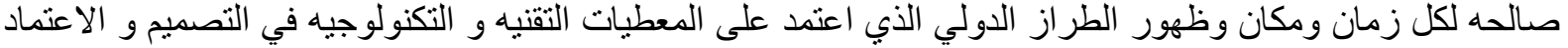

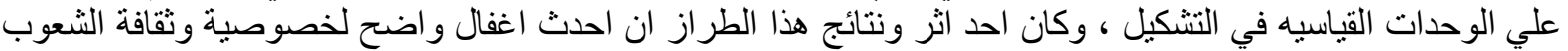

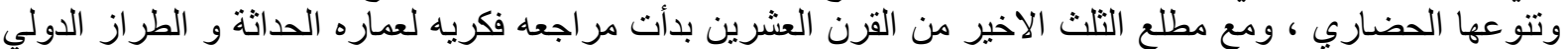

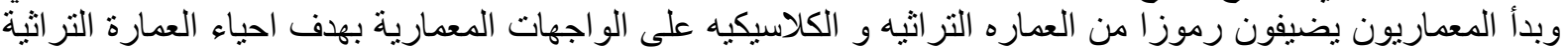

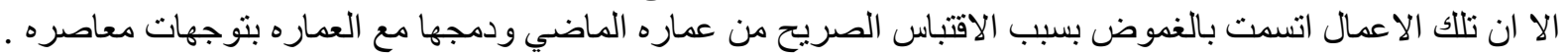

ثُ ظهر بعد ذلك في اخوار القرن العشرين توجه نحو البحث و التحليل في مضمون المفاهيم و الافكار الخاصة بالعمارة

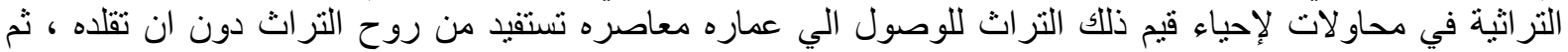

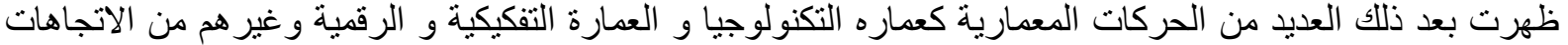

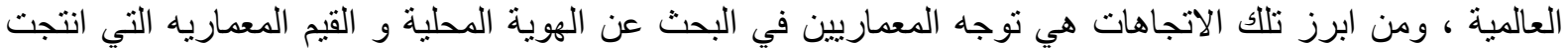

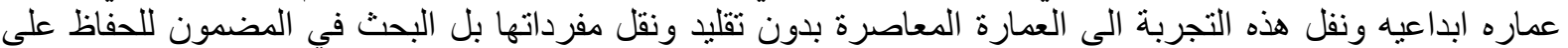

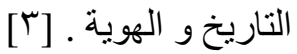

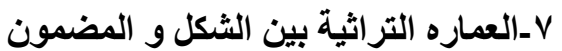

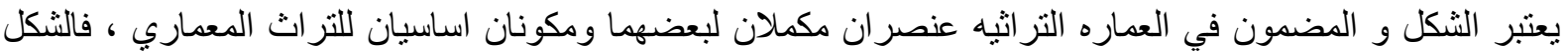

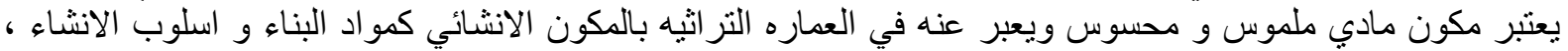

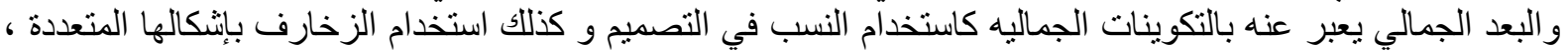

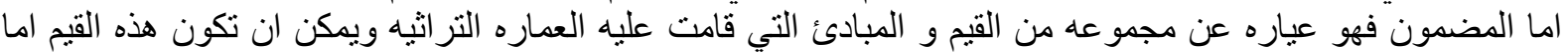

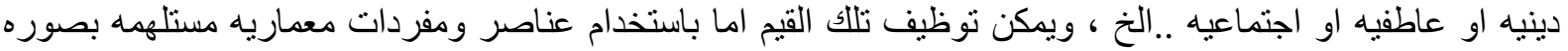

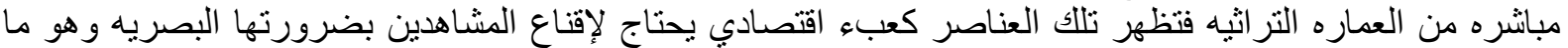

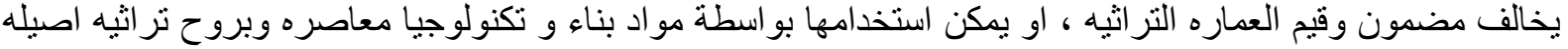

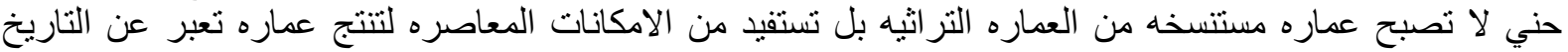

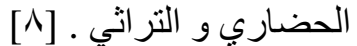

يـالاتجاهات الفكرية بين التأصيل و التجديد

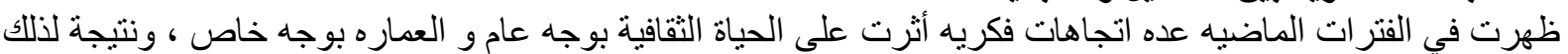

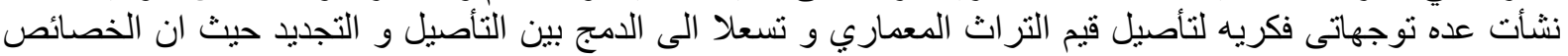

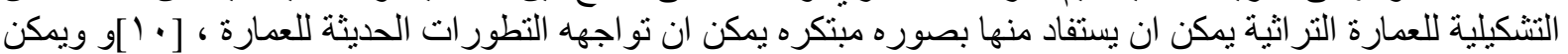

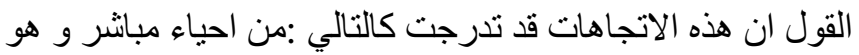

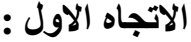

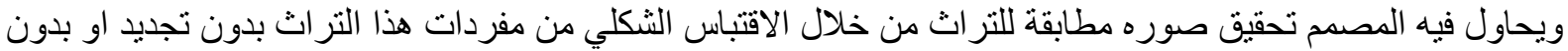

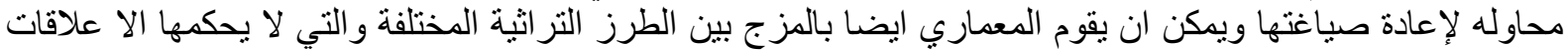


ROOTING THE ARCHITECTURAL VALUES OF HERITAGE IN THE CONTEMPORARY ARCHITECTURE

تتكيليه محسوسة مع اعتبار المدلول الثقافي المنقول من كل طراز ومدي ملائمته للواقع الثقافي و هو ما يطلق عليه

البعض اسلوب التأصيل بالتقليد او الاحياء المباشر ـ [10]

الاتجاه الثاني:

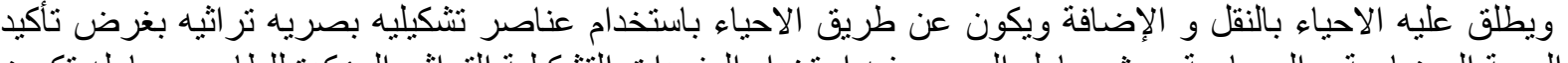

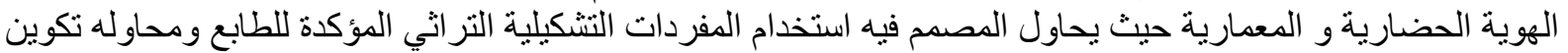

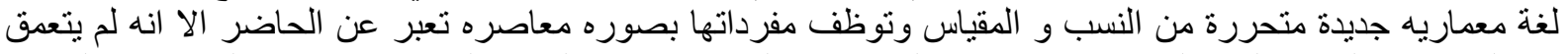

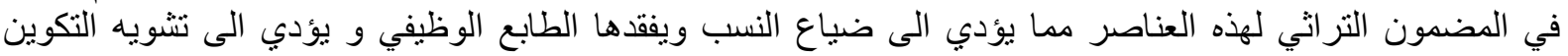

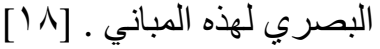

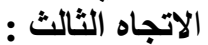

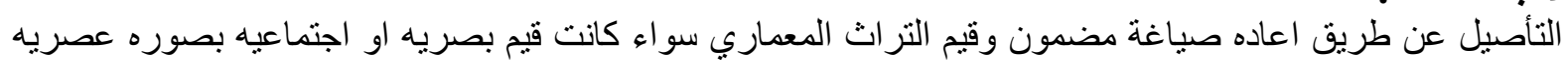

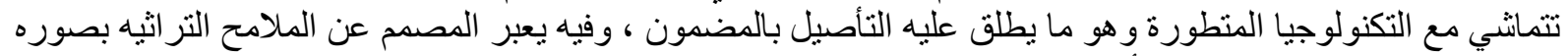

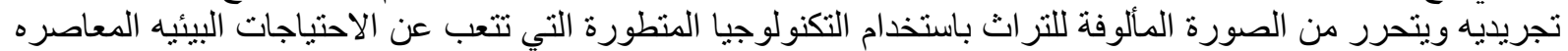

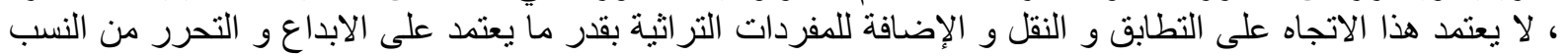

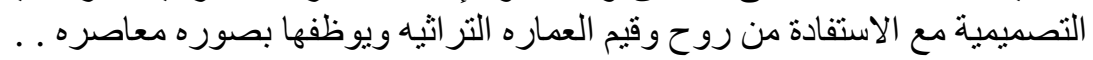

9

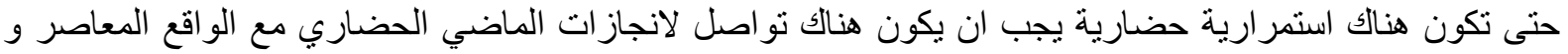

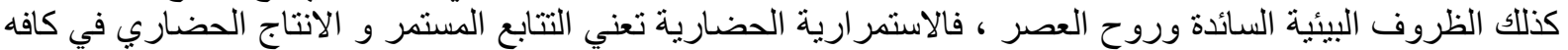

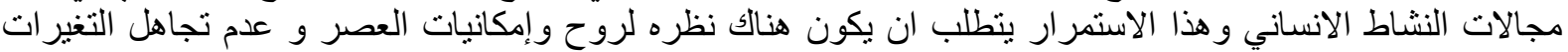

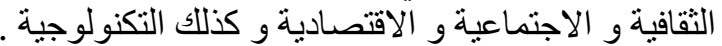

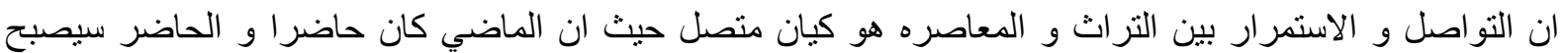

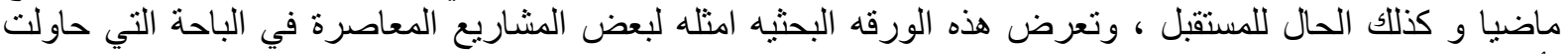

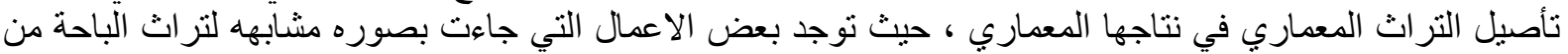

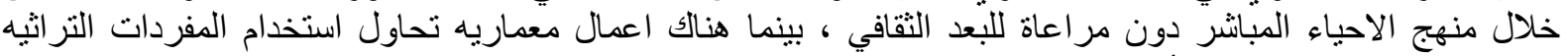

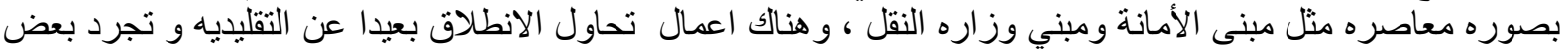

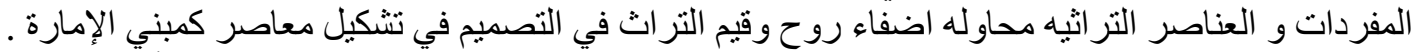

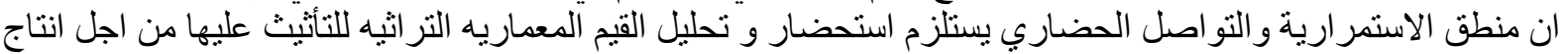

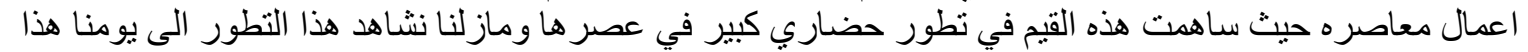

. 1 ـمقترح احياء القيم التراثية في عماره مدينه الباحة

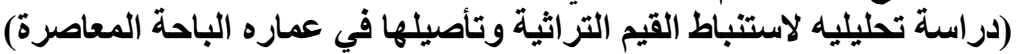

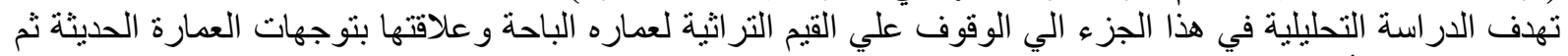

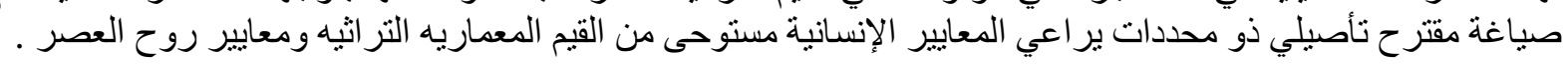

. 1 ـ التاريخ:

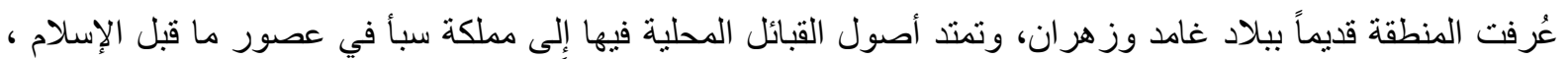

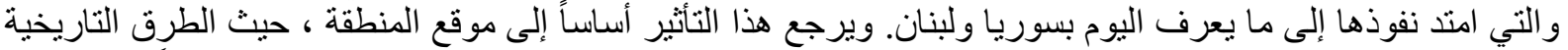

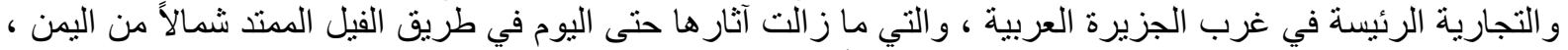

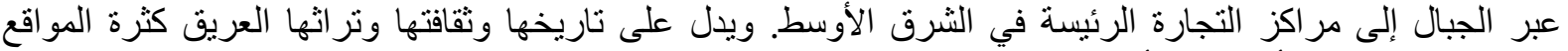
التاريخية بشكل يفوق أي منطقة أخرى بالمملكة التئة

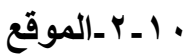

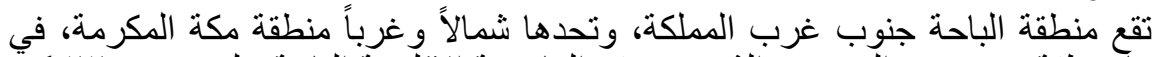

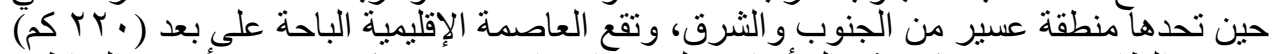

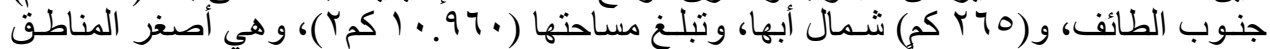

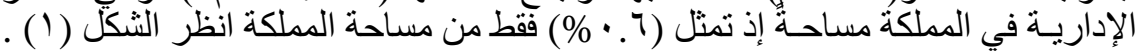




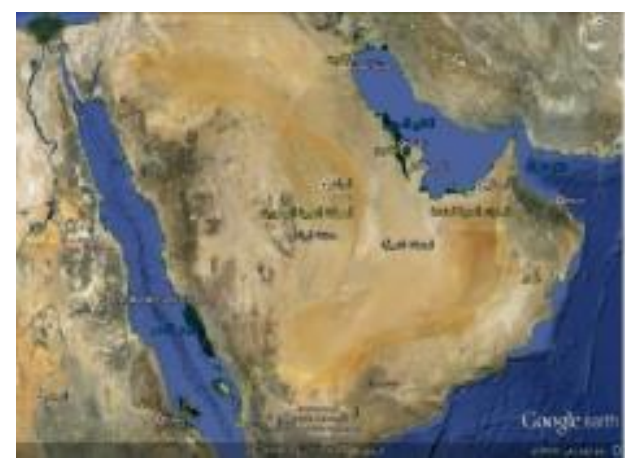

شكل ( ) : يوضح موقع الباحة بالنسبة للمملكة
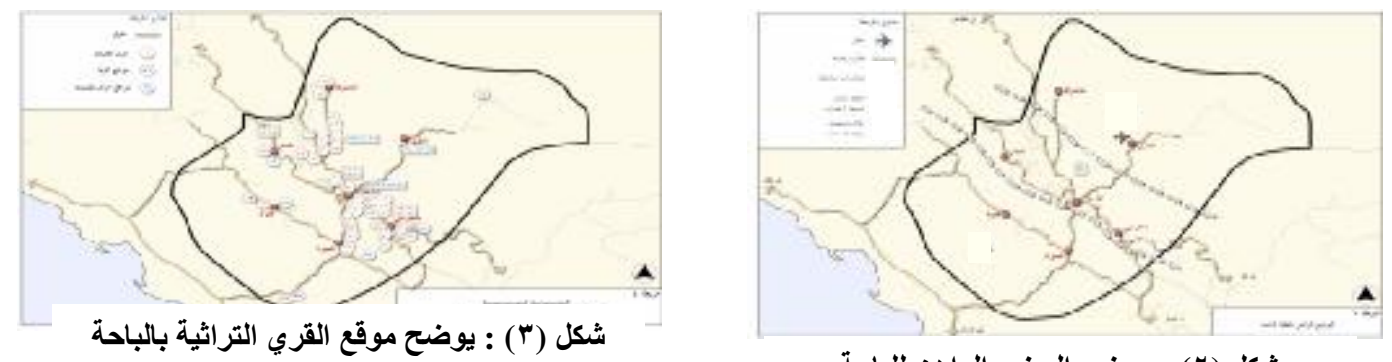

شكل (ץ) : يوضح الوضع الراهن للباحة

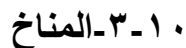
مناخ الباحة بشكل عام تتمتع المنطقة بمناخ جبلي معتدل حار نسبيا صيفا معتدل شتاءاً ، وتنتشر فيها الغابات الكثيفة، كما

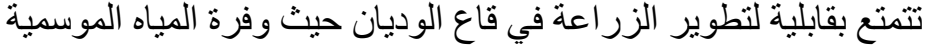

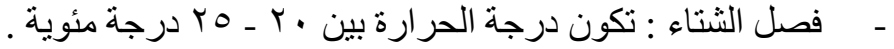

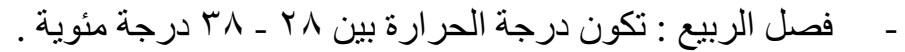

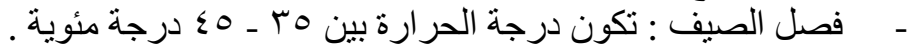

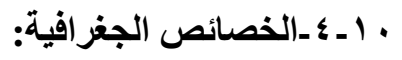

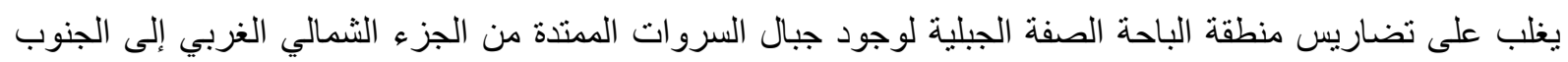

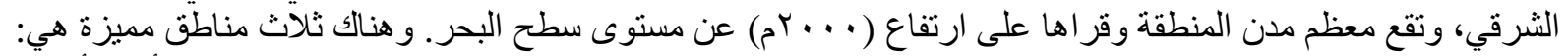

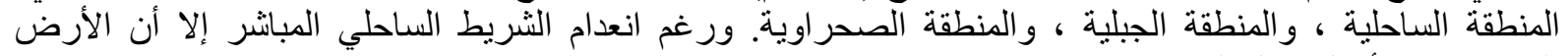
المنخفضة في أسفل جبال السروات ذات مناخ الطنة حار ورطب،

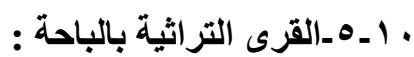

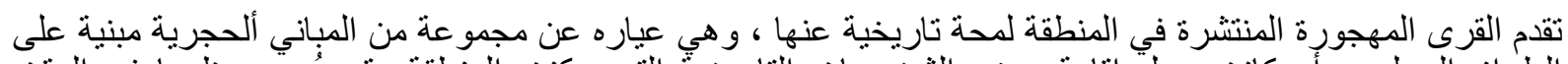

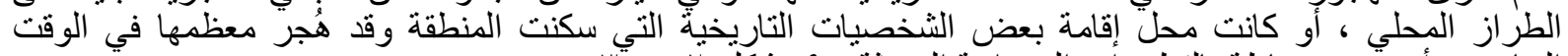

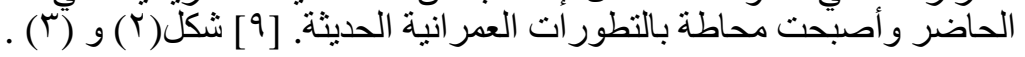

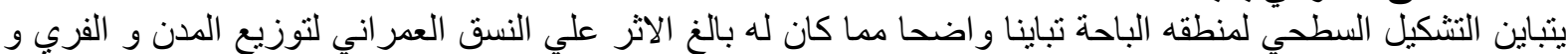

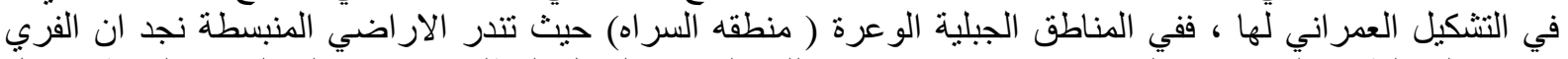

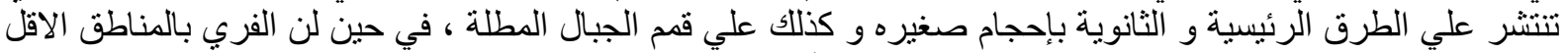

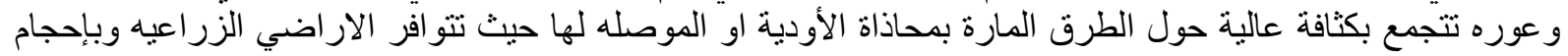

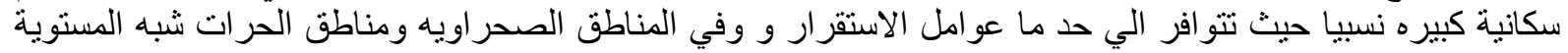
شرقا تتنتر الفري على مسافات بعيده و في احجام صغيره نسبيا ودائما ترنبط بشيكه الطرق الصنيا الصحر اويه 


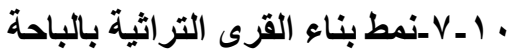
نجد أن الفري التراثية بالباحة قد اختيرت أن تنبى على مكان مرتفع وذلك لأغر اض دفاعية و أيضا لتكون عملية مر اقبة

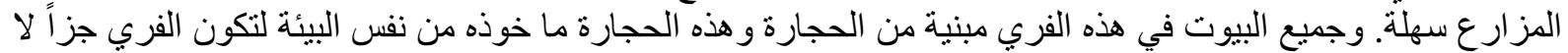

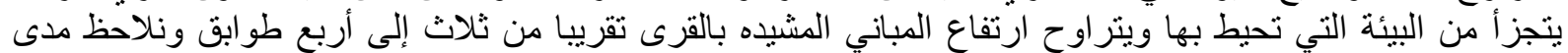

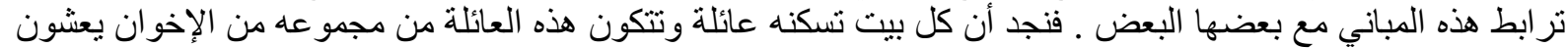

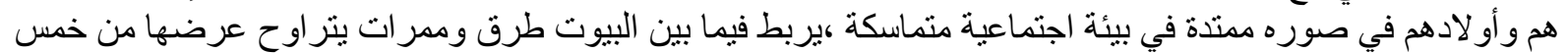

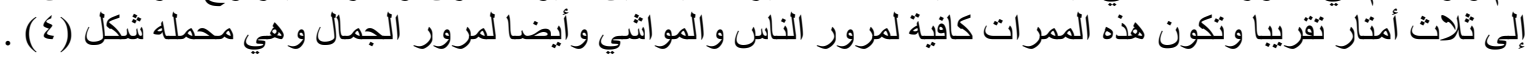

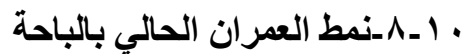

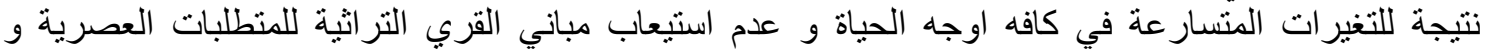

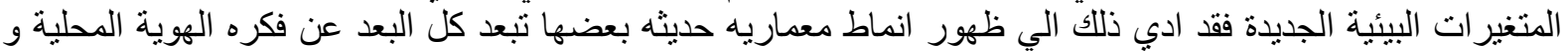

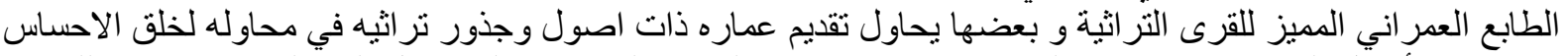

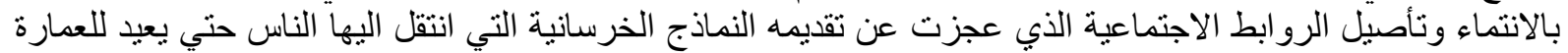

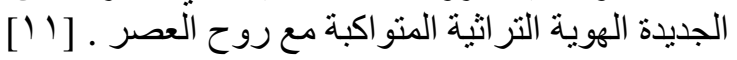

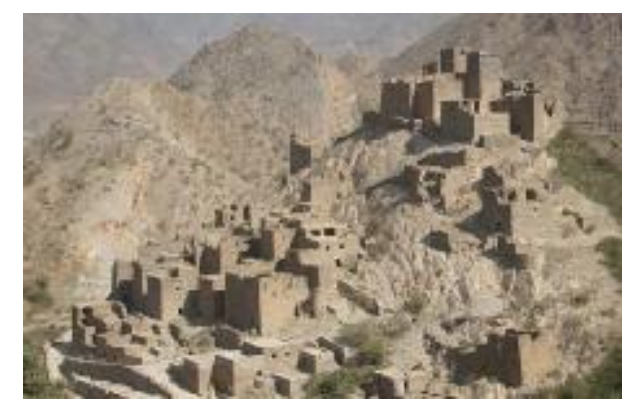

شكل ( ؛ ) : يوضح نمط بناء القرى التراثيه على قمم الجبال

11 القيم المعمارية التراثية المحلية في عماره الباحة

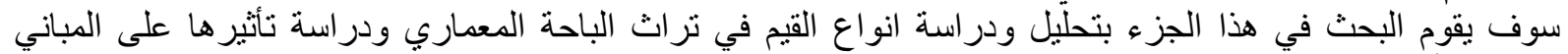

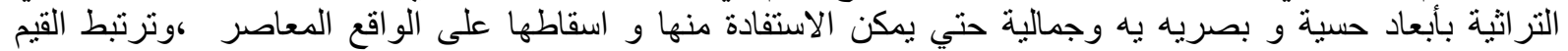

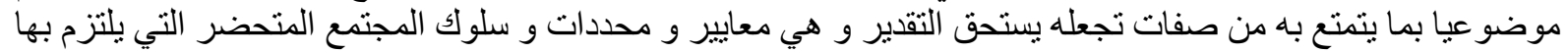

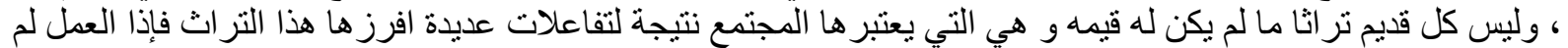

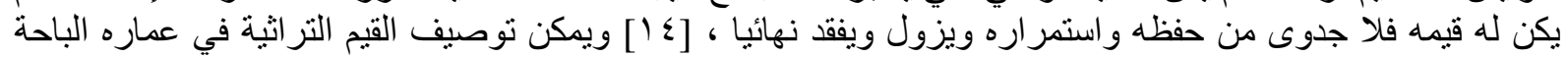
التي تم تحليلها الى المجمو عات التاليه :

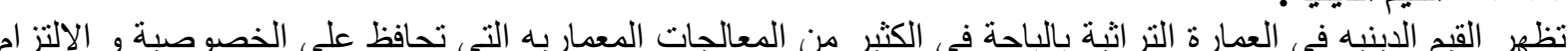

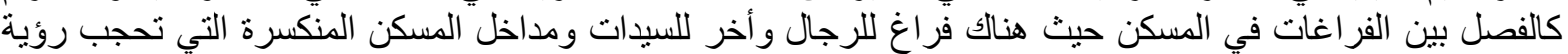

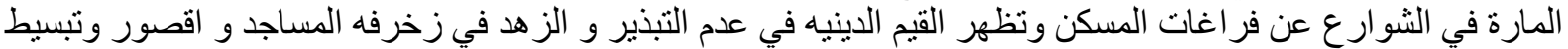
وتجريد المفردات الثكليه ، و هناك القيم الدينيه الحسيه التي تمثل البساطه كالمباني التي تخدم المساكين و عدم تشيييد مباني

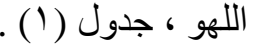

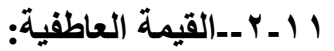

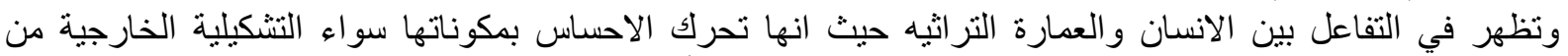

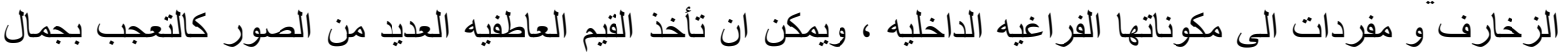

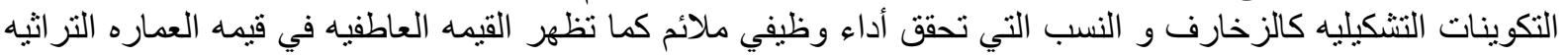

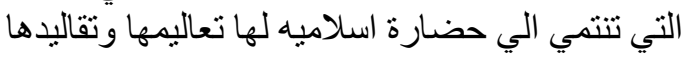


ROOTING THE ARCHITECTURAL VALUES OF HERITAGE IN THE CONTEMPORARY ARCHITECTURE

ولذللك نجد استمرار هذا التراث وملائمته للتطورات الإنسانية في قو الب نتناسب مع روح العصر وهئ وهنالك ايضا القيمة

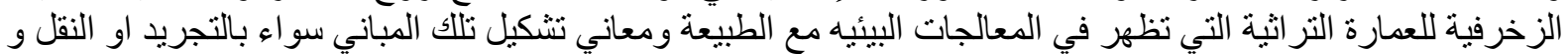

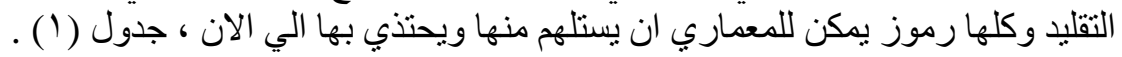

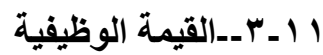

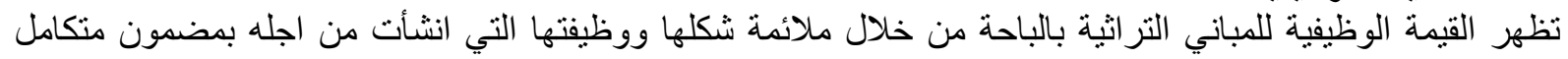

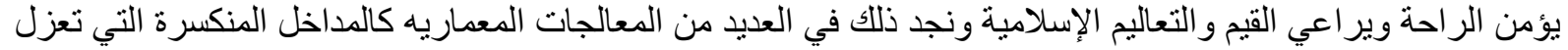

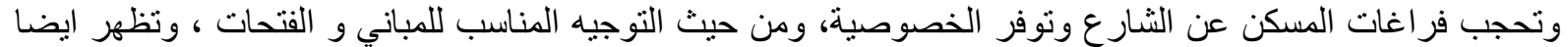

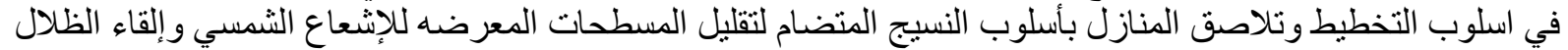

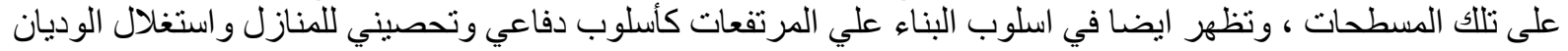

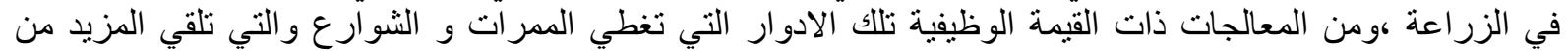

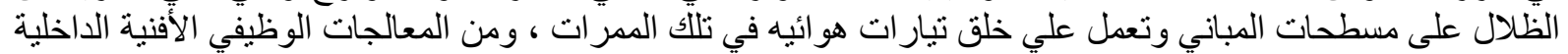

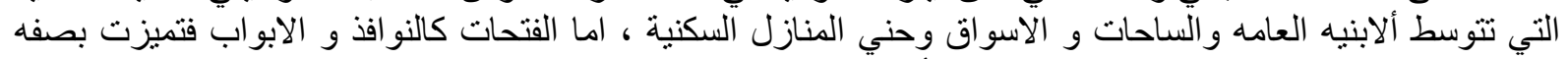

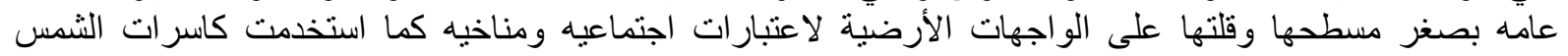

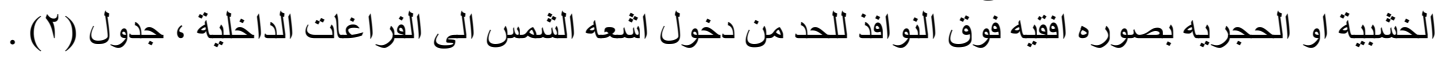

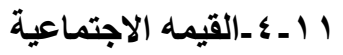
وتظهر القيمه الاجتماعية من خلال تصميم فر اغات المبات المباني و المعالجات التي تحقق كل من الخصوصية وحقوق الجار

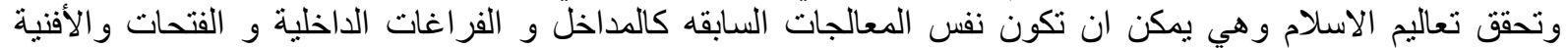
و النسيج العمر اني للقرى المنضام التي يمكن ان تحقق اكثر من قيمه سو اء وظيفية او دينيه او اجتماعيه ، جدول (r) .

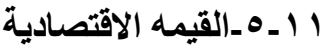

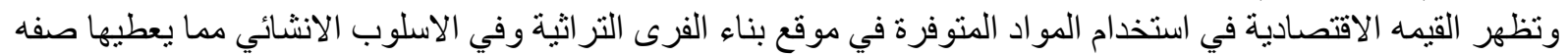

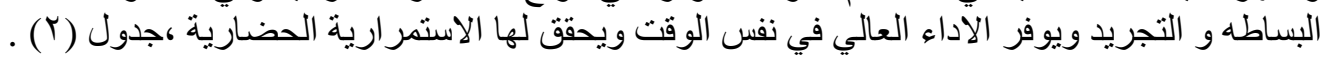

في القيز القيمه التاريخية

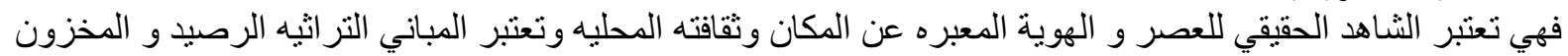

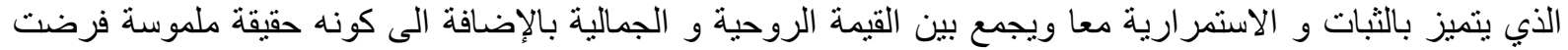

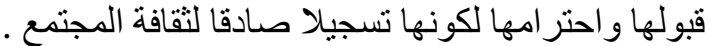
ومن خلال هذا التاريخ يمكن استلهام اسلوب المعالجات والتصميمات في الاعمال المعاصره لتميز طرزها المعماريه ،

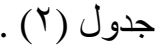

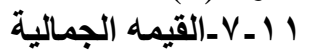

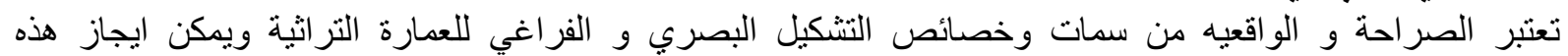

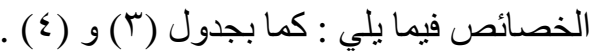

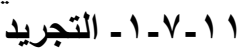
يعتبر الدين الاسلامي وتعاليمه السمحة البسيطة هما مصدر الالهام للأشكال البسيطة المجرده للعمارة التراثيه

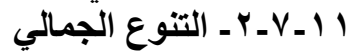

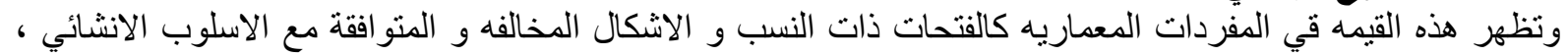

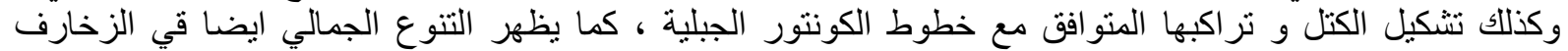

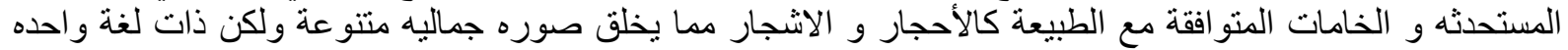

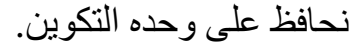

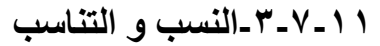

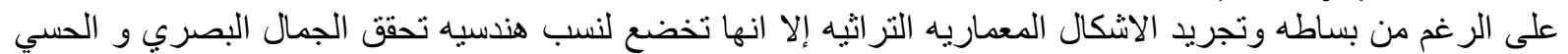

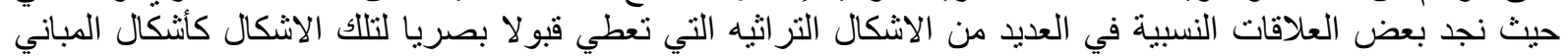

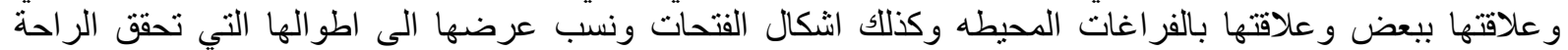

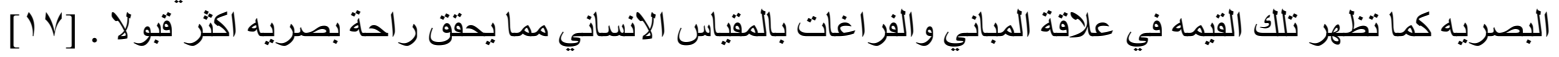

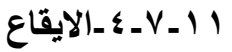

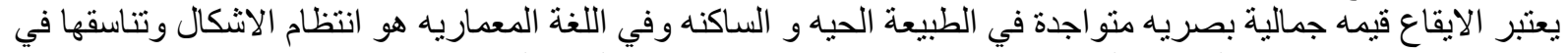

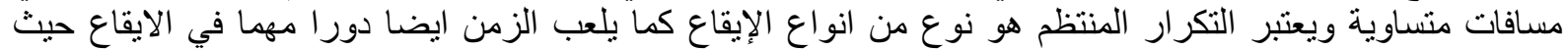

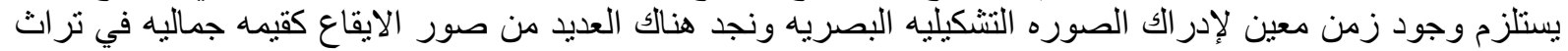




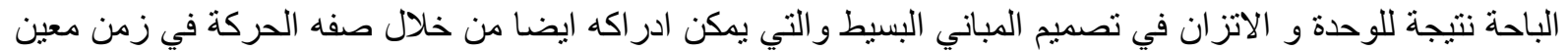

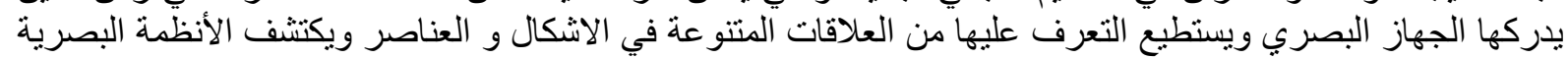

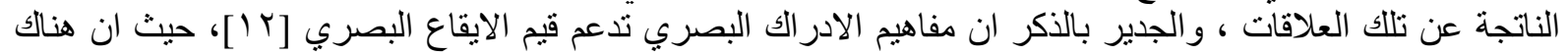

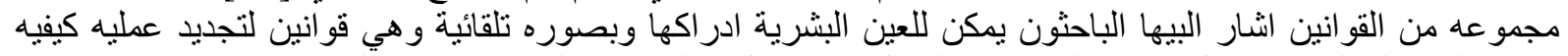

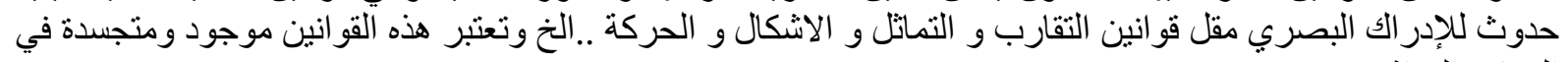

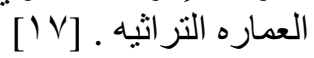

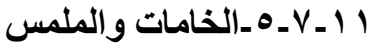

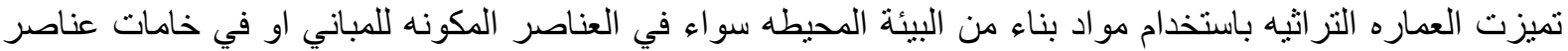

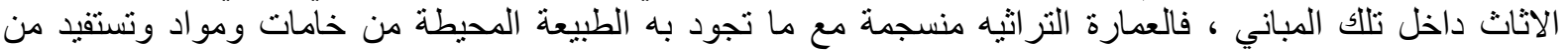
معطيات تللك الطبيعة

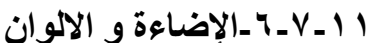

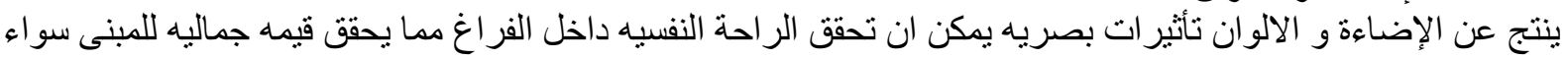

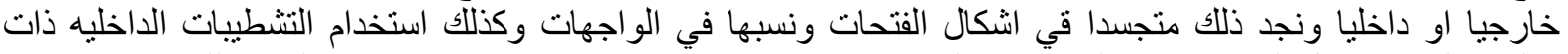

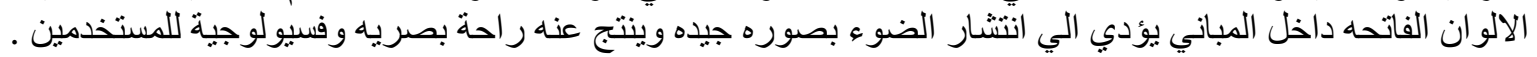

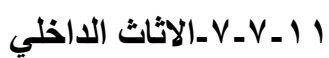

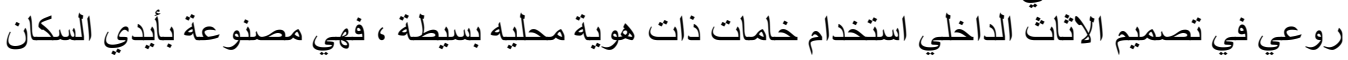

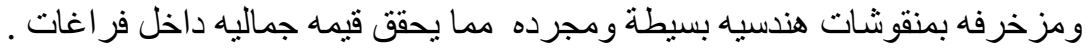

\section{r ا ـاتجاهات الربط بين التراث و المعاصره في الباحة}

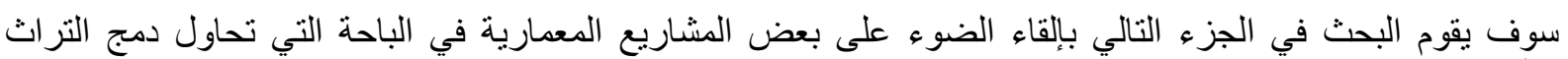

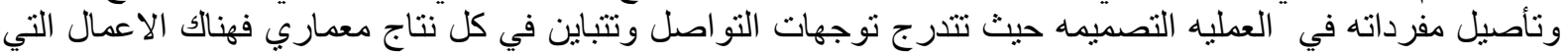

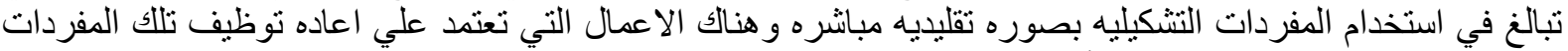

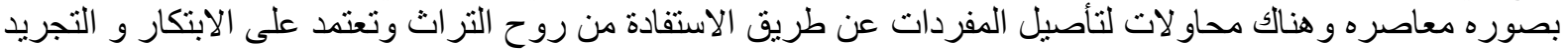

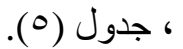


ROOTING THE ARCHITECTURAL VALUES OF HERITAGE IN THE CONTEMPORARY ARCHITECTURE

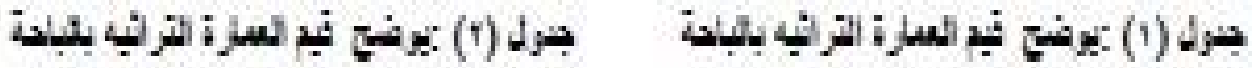

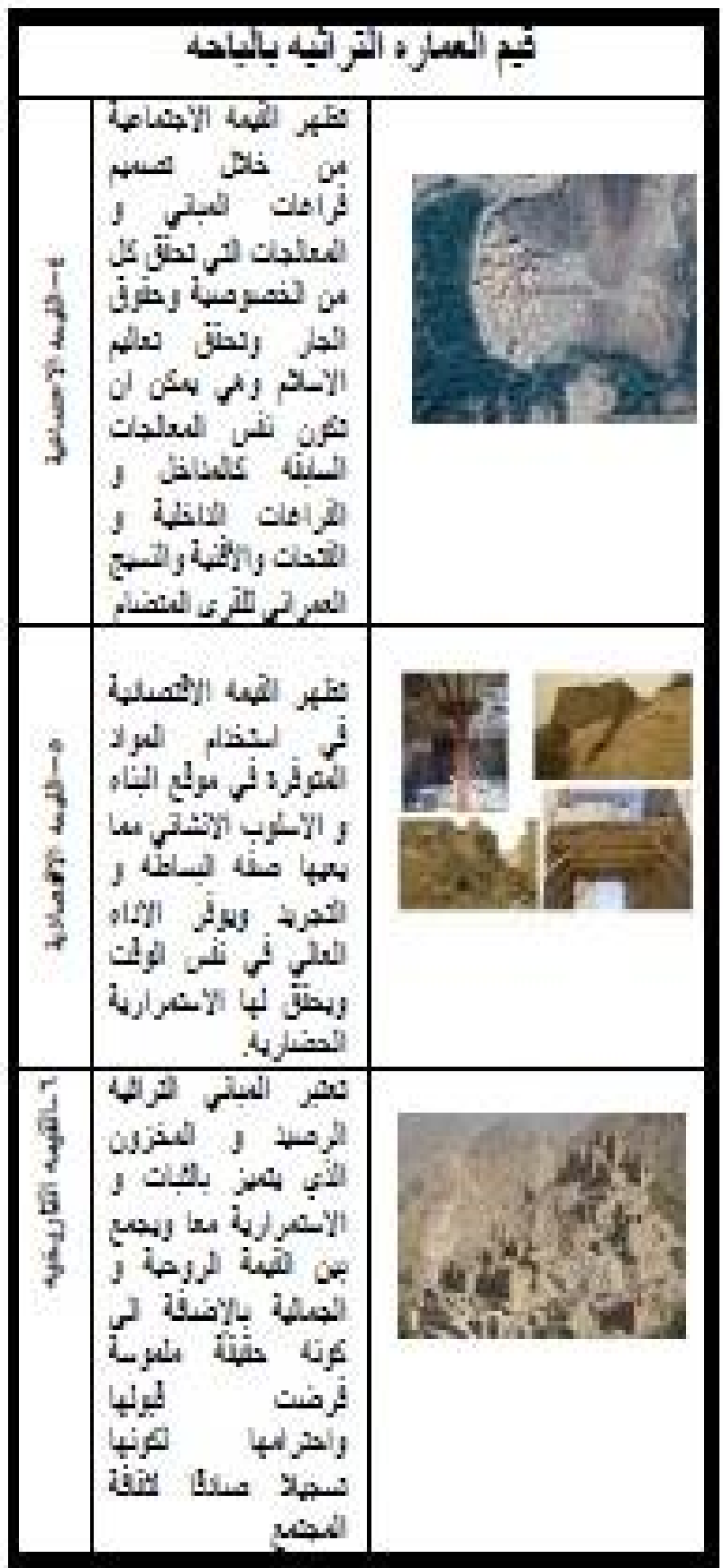

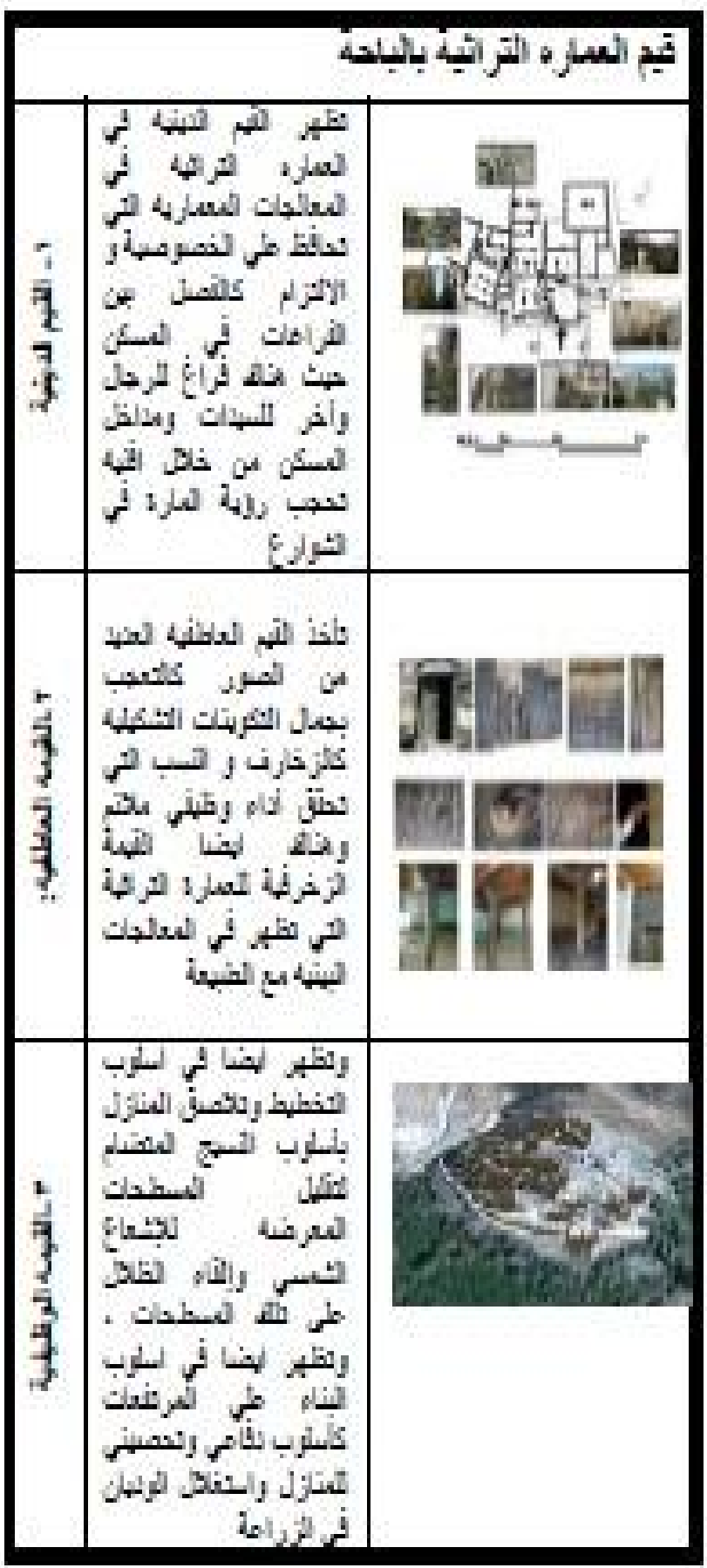


ROOTING THE ARCHITECTURAL VALUES OF HERITAGE IN THE CONTEMPORARY ARCHITECTURE

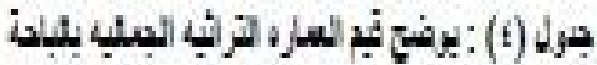

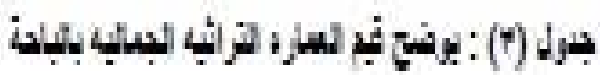
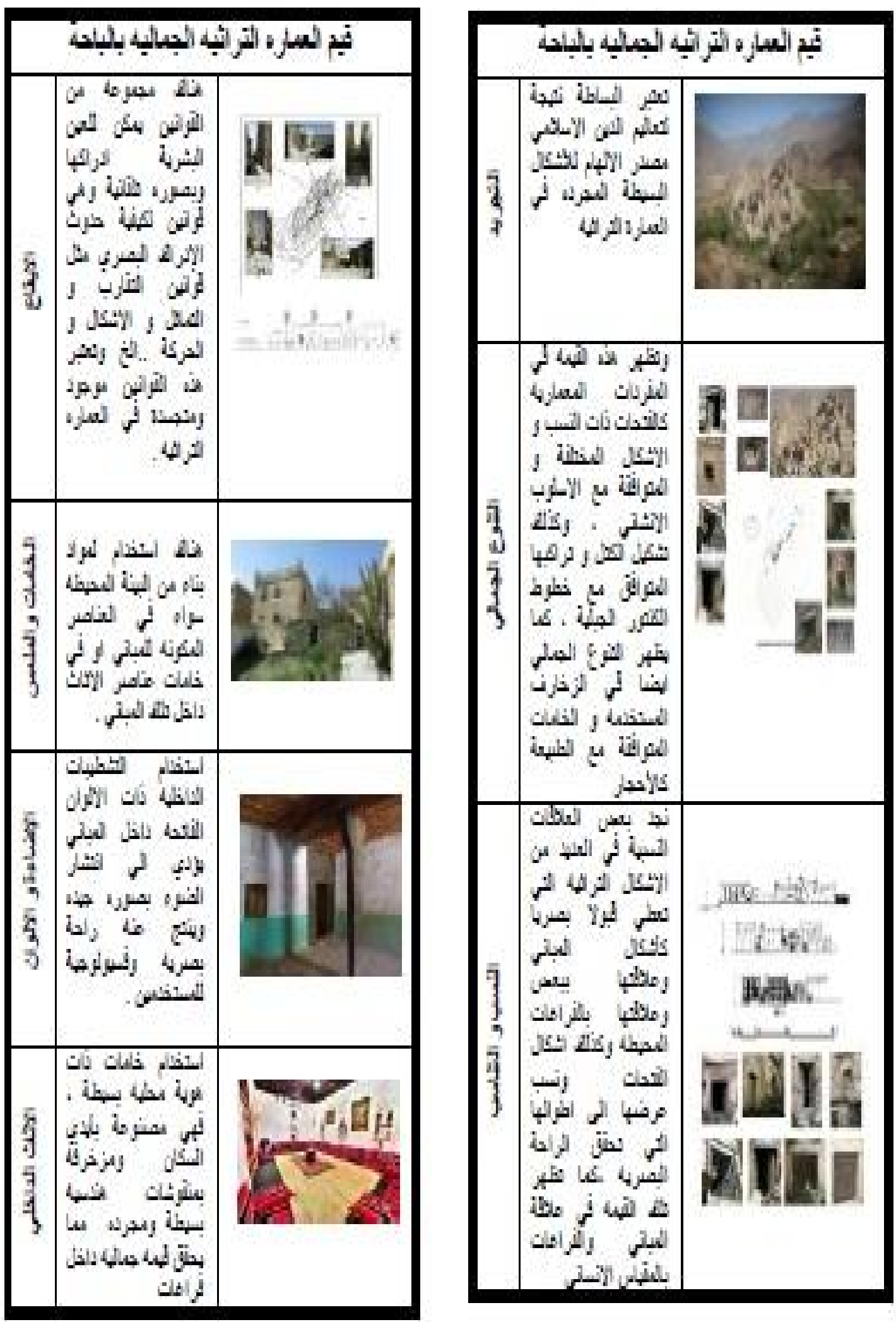
جدول (ه): اتجاهات الربط بين التراث و المعاصره

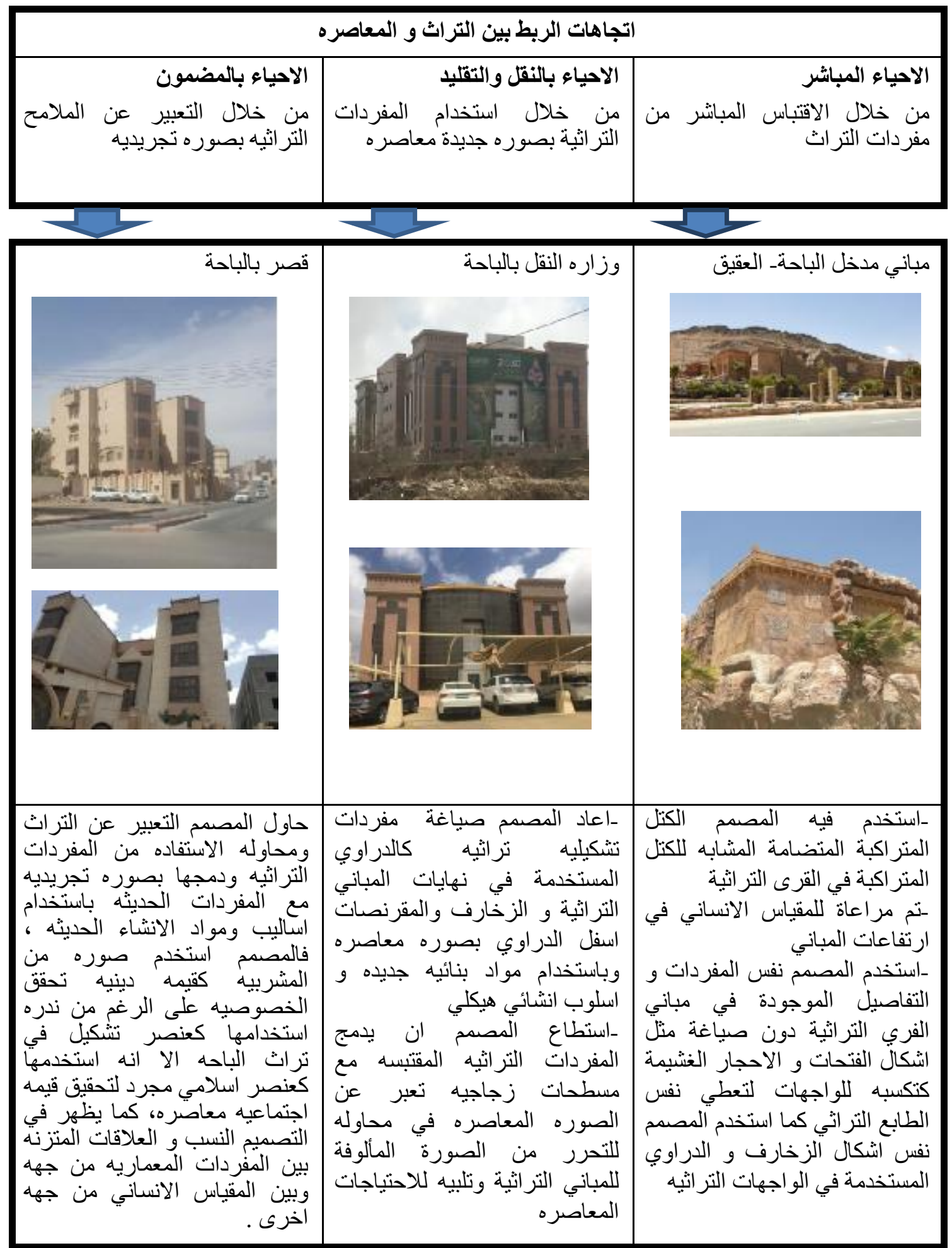




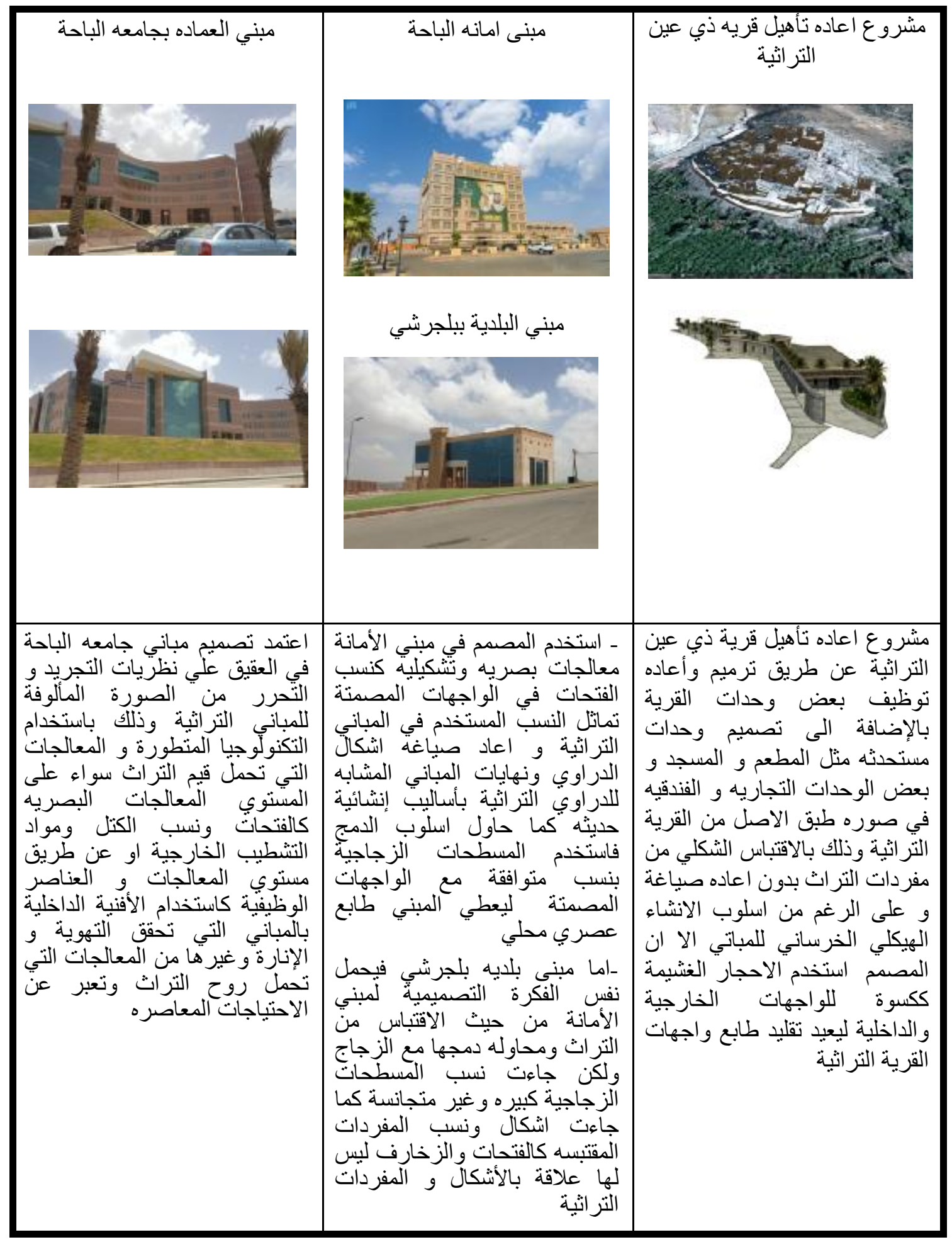




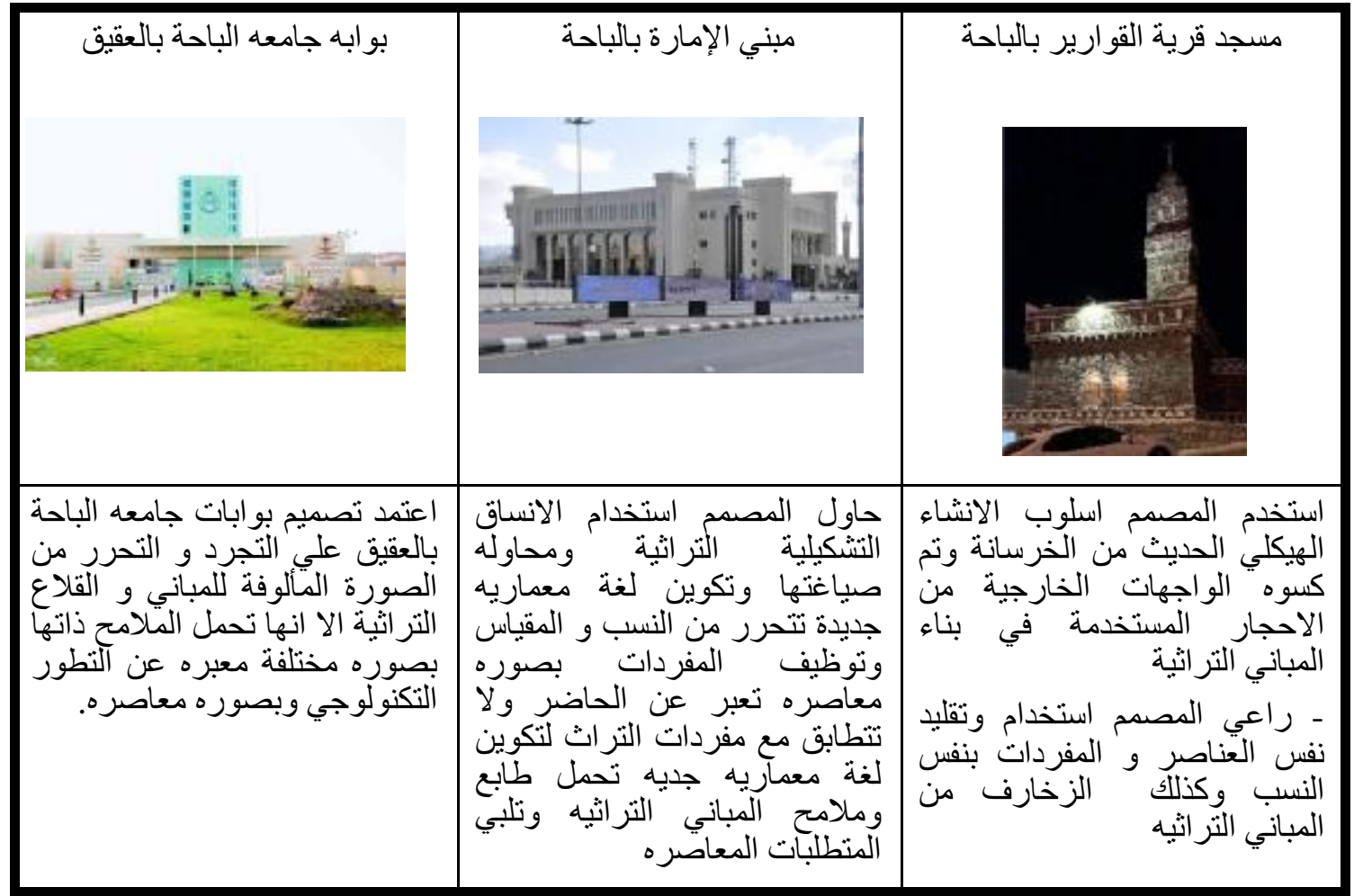

با 1 ـمقترح لتأصيل القيم المعمارية التراثية في عماره الباحة المعاصرة

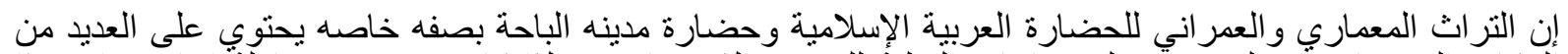

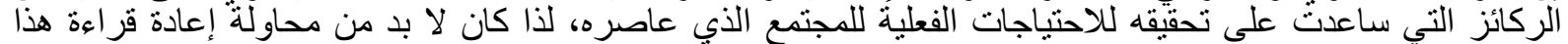

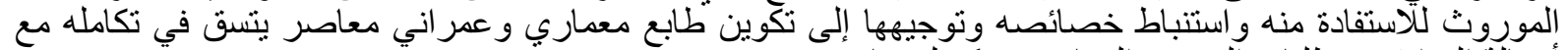

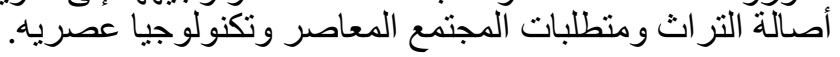

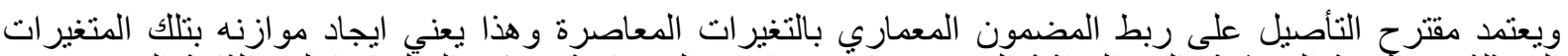

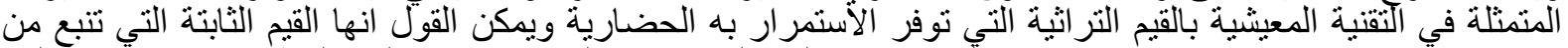

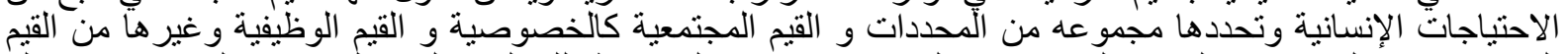

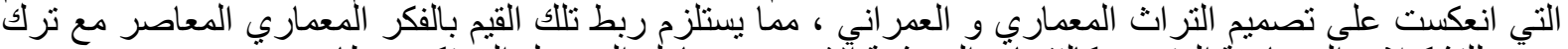

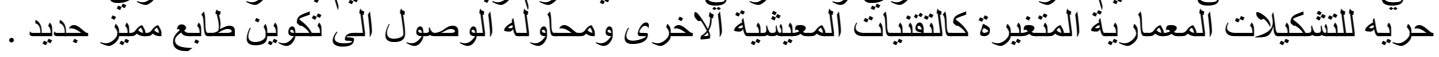

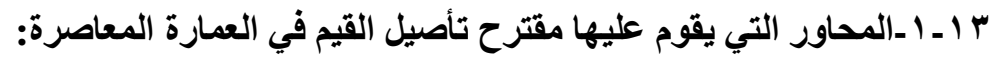

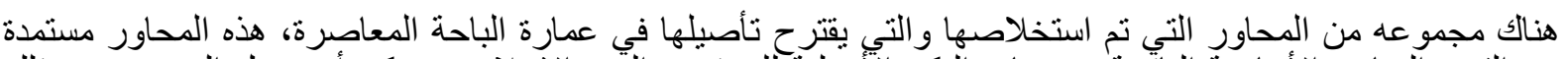

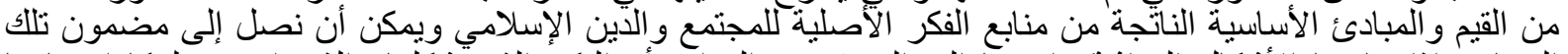

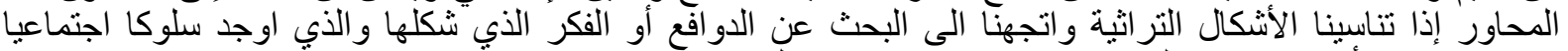

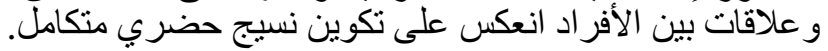

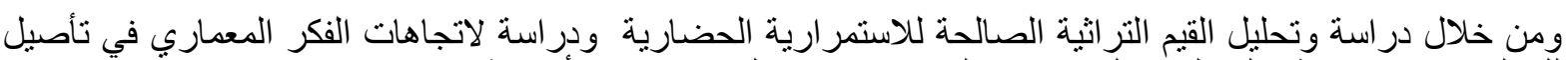

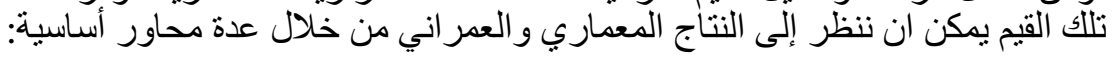

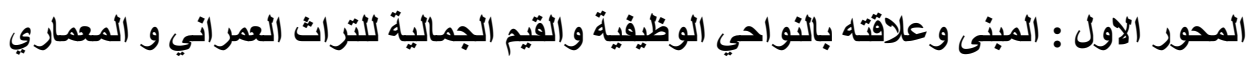

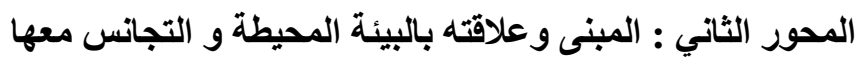

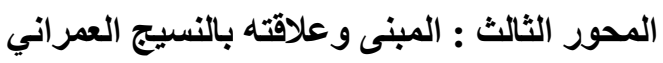

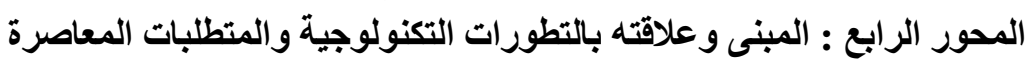

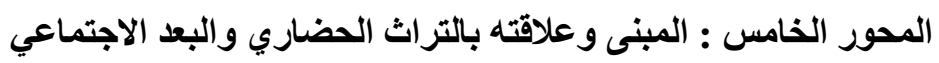
المحور السادس : المبنى و علاقته بالاستمرارية الحضارية.

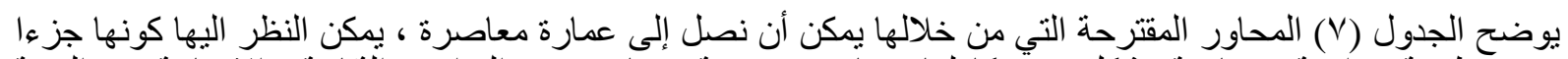

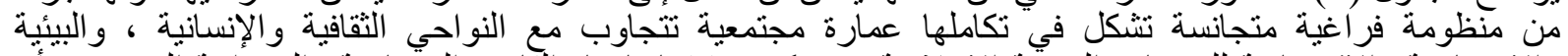

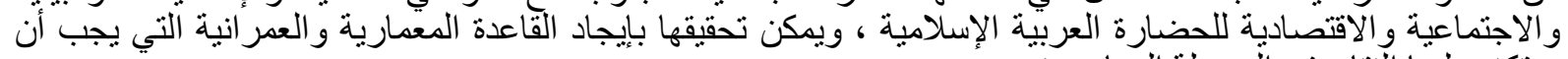

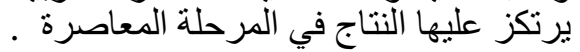




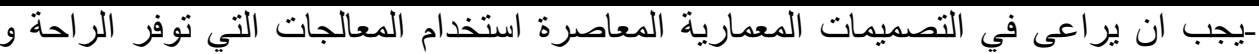
تحقق الوظيفة التي انشات من اجلها كالمداخل المنكسرة و الفتحات ذات النسب القليلة واستخدام

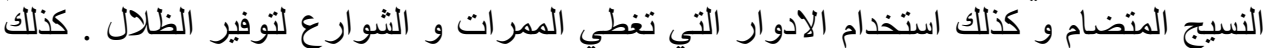
خلخله المباني بالفراغات و الأفنية التي تحقق الخصوصية وتوفر التهوية الجيدة للفر اغات التئ المحيطة

ـ مر اعاة القيم الجمالية في التشكيلات المعمارية للمباني الحديثة ويعتبر الدين الاسلامي هو مصدر

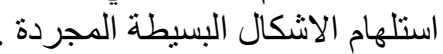

ـ ضرورة الاهتمام بالمفردات و التفاصيل المعمارية كنسب الفتحات و تشكيل الكتل و تر اكبها المنسجم مع طبو غر افية الموقع و استخدام الخامات من الطبيعة.

ـ مر اعاة استخدام الاشكال المعمارية التي تحقق الوظيفة لإنشائية وتتوافق مع المقياس الانساني مما يحقق راحة بصريه

ـضرورة الاعتماد على مو اد البناء البيئية في عناصر الفرش و خاماته بأثكال بسيطة ذات هوية محليه مصنو عة بأيدي السكان مما يحقق قيمه جمالية داخل فر الينا الينة في اغات المباني .

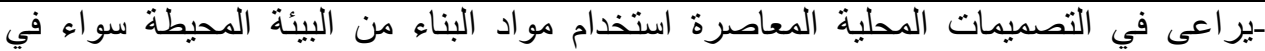

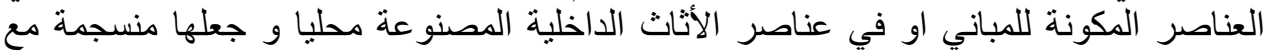
المعطيات البيئية المحيطة.

-يراعى استخدام تشطيبات داخليه ذات الوان فاتحه لتحقيق الراحة النفسية و البصرية داخل

ـالاهتمام بالمعالجات البيئية التخطيطية والتصميمية و تشجيع المعداريين على ايجاد حلول بيئية مستدامة تحقق الر احة لشاغلي المباني المعاصرة بدون اللجوء للوسائل و التركيبات الميكانيكية -يمكن الاستفادة من الاداء البيئي للمباني التر اثية ، و الوقوف على مستوى ادائها في وضع الحلول

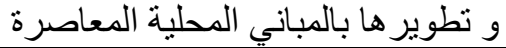

-يجب ان يكون هناك اشتر اطات من قبل الجهات المسئولة لتقييم الاداء البيئي للمباني المعاصرة

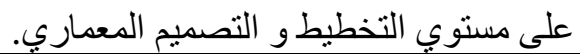
-يعتبر النسيج العمر اني المتضام من افضل البدائل التخطيطية للقرى بالباحة لما يحقق من قيمه وظيفية و اجتماعيه ، كما يجب مر اعاة خطوط الكنتور لخلق تدرجات بنائيه تحقق قيم و معايير وظيفية و مناخيه

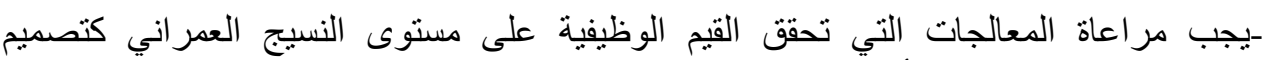

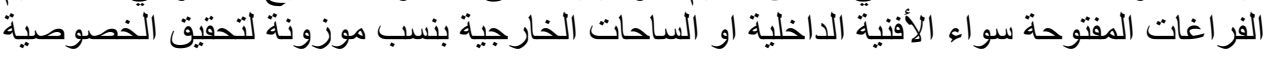

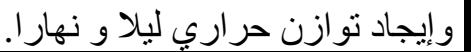
-يجب ان يكون في تصميم النسيج العمر اني فصل في استخدام الاماكن العامة كالأسواق و الاماكن الاينية وبين الاماكن السكنية.

-يجب ان يكون هنالك تسلسل في الفراغات البنائية بحيث تحقق المتطلبات الاجتماعية و الثقافية 
ROOTING THE ARCHITECTURAL VALUES OF HERITAGE IN THE CONTEMPORARY ARCHITECTURE

-ضرورة الاهتمام بتصميم شُبكه الطرق و المررات الرئيسية و الفرعية التي تخدم التجمعات

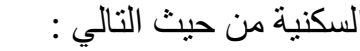

ـ تحديد عروضها لاستيعاب خدمات البنيه الأساسية و مرور وسائل الحركة الحديثة مع الحفاظ

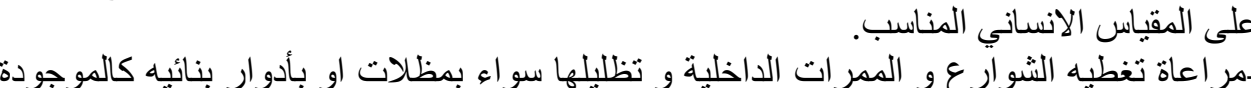

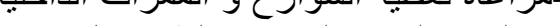

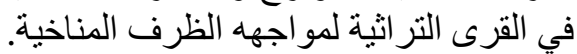
-ضرورة فصل حركه المشاة عن حركه السيار ات لتحقيق عامل الامان.

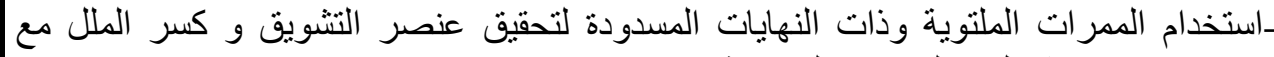

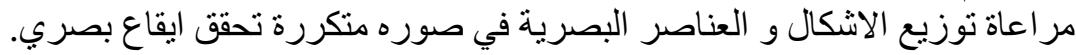

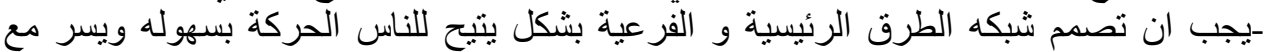
توفير مناطق لانتظار السيار ات. تصن.

-يجب وضع شروط للمعماريين توضح خامات ز مواد البناء و التشطيب الداخلي التي يجب وهوبـ الالتز ام بها عند التنفيذ. وصن.

-ضرورة البحث على الاتجاهات و الافكار المعمارية المعاصرة مع البعد عن التقليد الاعمى و النقل من مفردات التر ات بصوره مباثره ولصقها على الواجهات الحديثة او التجاه الى التهمة التصميمات الغربية البعيدة عن الهوية المحلية.

-ير اعى في التصميم فكره التأصيل و الاحياء باستخدام روح العصر و التعبير عن الملامح التراثية بصوره تجريديه.

ـالتشجيع على استخدام النظم الإنشائية الجديدة في العمارة المحلية وكذلك استخدام المواد الجديدة التي يمكن استخدامها في قطاع انشاء المباني المحلية المعاصر.

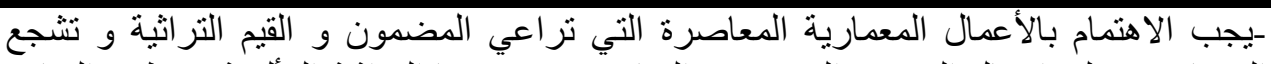

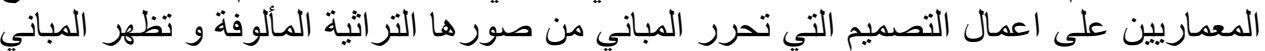
بطابع محلي معاصر ذو صور عه ابداعيه. ـضرورة اشر الك الاهالي في مقترحات الشكل و المضمون للطابع العمر اني المعاصر. -يجب وضع معايير وأسس تر اعي الجوانب الاجتماعية و الإنسانية للمجتمع المحلي و تخدم التراث بقيمه و مضمونه وبقالب معابير معاصر.

ـالتأكيد على أهميه القيم الدينية وتعاليم العقيدة الإسلامية كأداة لمتابعه مسيره الانتاج المعماري و و

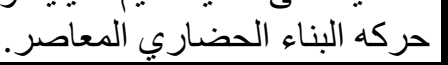

ـعدم تقييد الفكر المعماري و تحديد توجيهات التصميم في التكوينات البصرية التراثية القديمة و التشجيع على مقترحات التشكيل البصري المعاصرة توبيد التي تراعي مضمون القيم التر اثية.

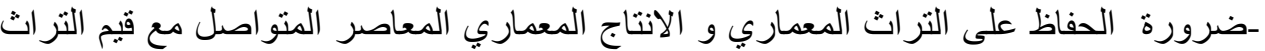

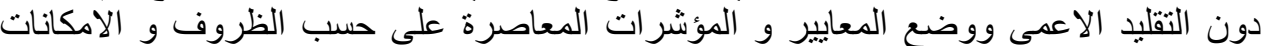

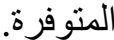

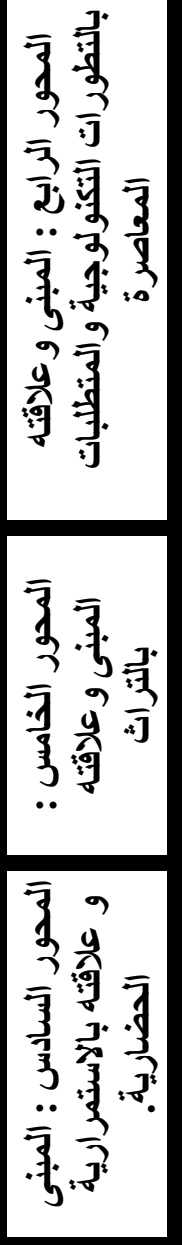

الخلاصة

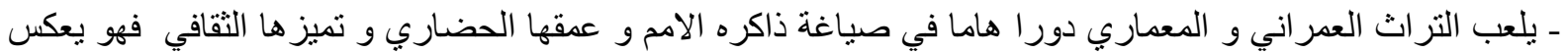

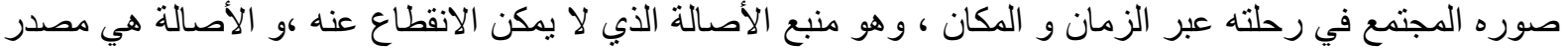

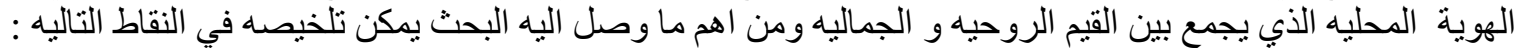

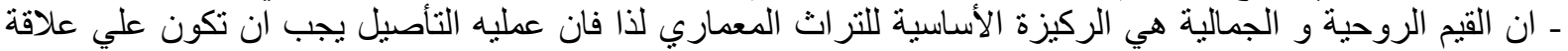

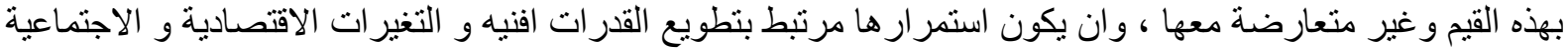

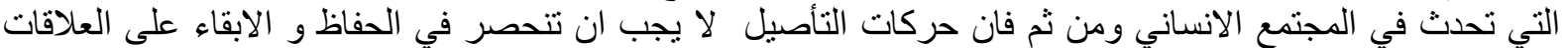

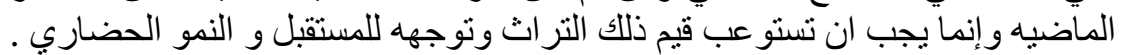


ROOTING THE ARCHITECTURAL VALUES OF HERITAGE IN THE CONTEMPORARY ARCHITECTURE

ـهناك علاقة تكاملية بين التراث و المعاصرة فالتراث مرتبط بالتأصيل و المعاصرة مرتبطة بالتجديد و كل منهما له القيم

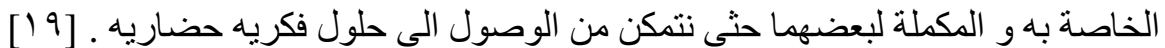

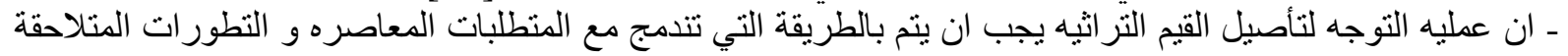

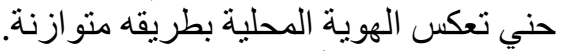

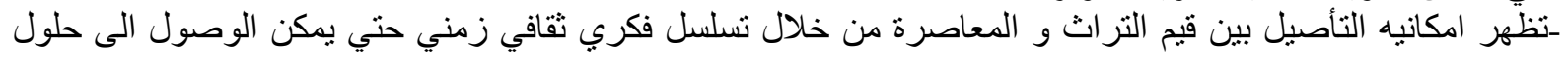
فكريه حضارية. ـ تحتوي العمارة التر اثية القديمة بالباحة علي خصائص بصريه نت تشكيلها بناء علي قيم وظيفيها و تاريخية و اجتماعيه و

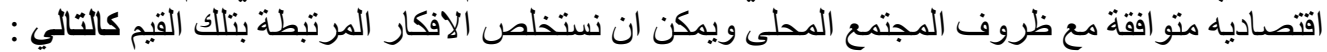

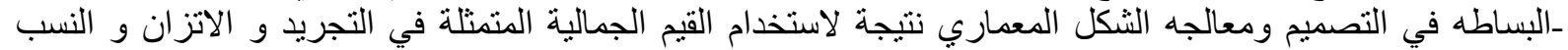
و غير ها من الافكار التي يمكن الاستفادة منها العمارة المعاصرة باقل التكاليف وبتكوينات بصريه جميله ومتلائمة مع الإنية خصائص البيئة المحيطه. -حقق تصميم عناصر ومفردات العمارة التر اثية قيمه وظيفيه و اقتصاديه نتيجة لاستخدامه مواد الانشاء البسيطة في شكلها

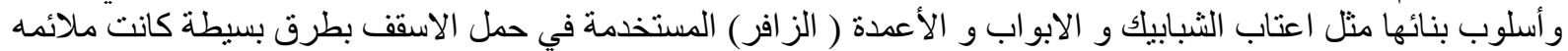

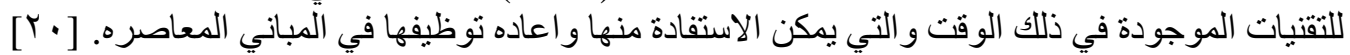

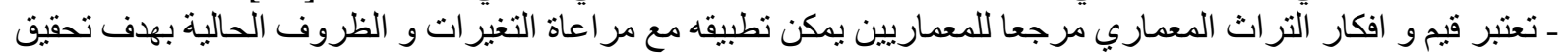

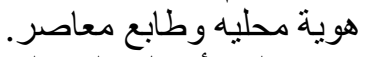

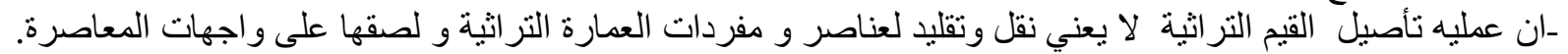

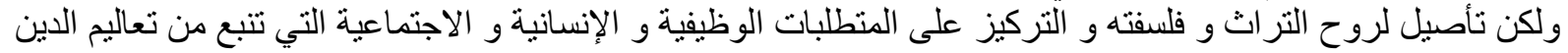

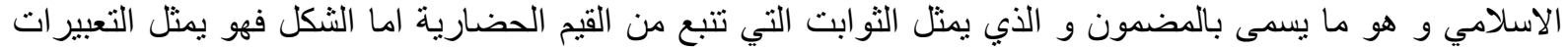

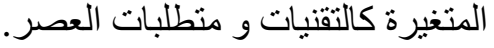

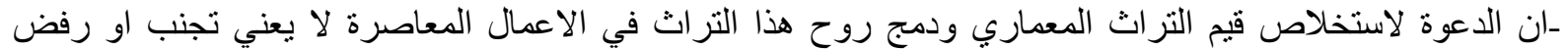

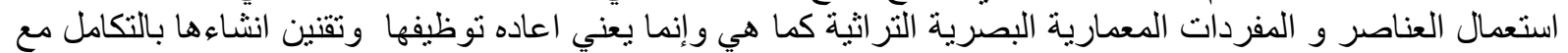
تلالك القيم

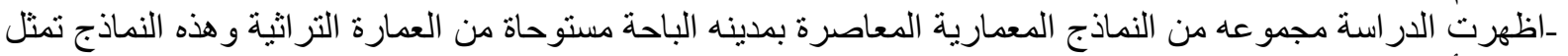

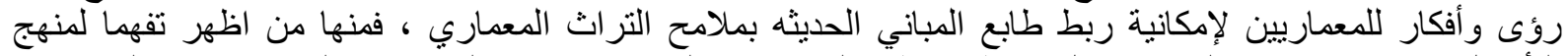

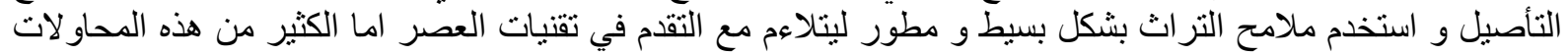

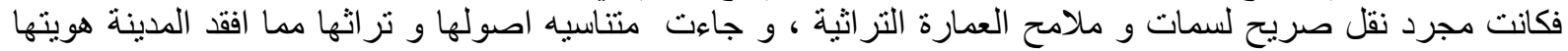
المحلية - جاءت الكثير من القيم التراثية كالقيم الدينية و الاجتماعية و الثقافية ثابتة بالر غم من متغير ات التير العصر بينما قيم التثكيل

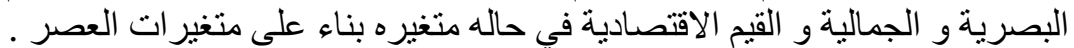
- نم تحقيق هدف الدر اسة من خلال صباغة مقترح يجمع بين القيم المعمارية التر اثية و رو روح و إمكانات العصر حني بمكن تطبيقه علي الواقع المعماري و العمر اني بمدينه الباحة.

ا. إسماعيل سراج الدين.(•99 (م). (التجديد و التأصيل في عمارة المجتمعات الإسلامية ). جينيف. مؤسسه

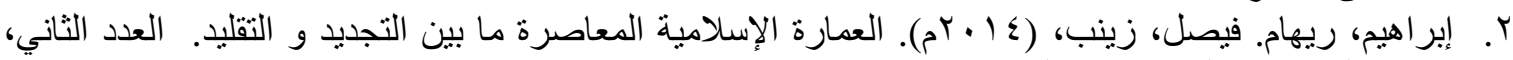

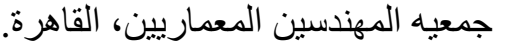

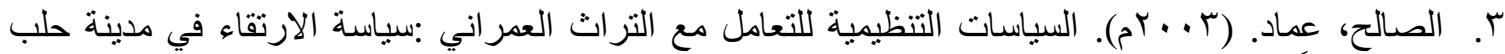

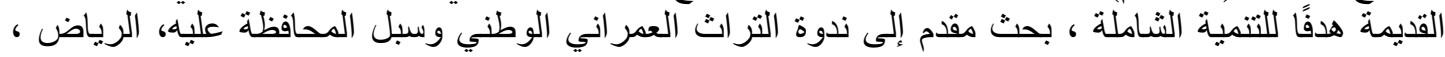

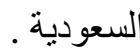

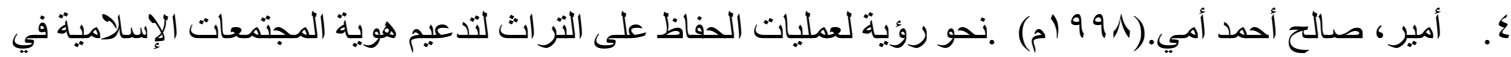

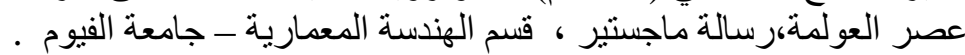

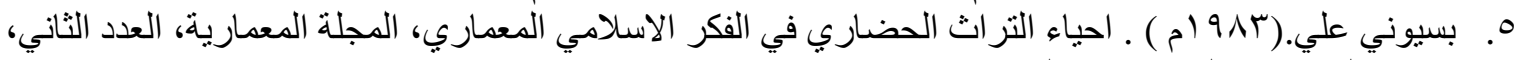
جمعيه المهندسين المعماريين، القاهرة. الفئ.

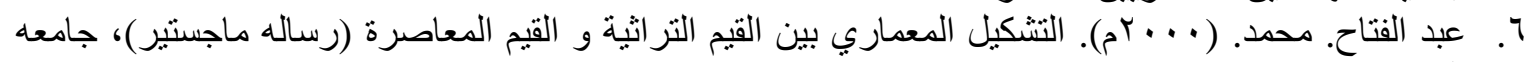

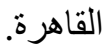
V. عبد الله ،يحي.(911 (م). من التراث، مجله المعمار، العدد 9، • (، جمعيه المهندسين المعماريين ، القاهرة ، 
^. ناجية عبد الغنى سعيد. (999 (م). نحو خطة قومية للحفاظ الايجابي على التراث البيئي ، المؤتمر التناسع

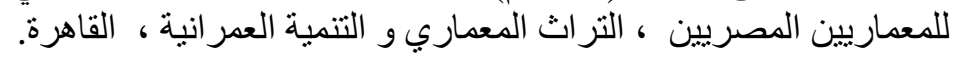

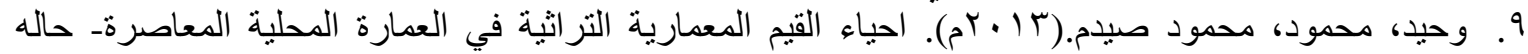

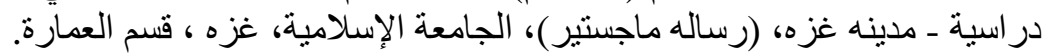

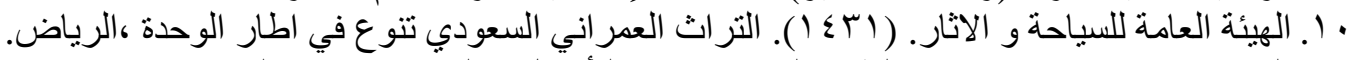

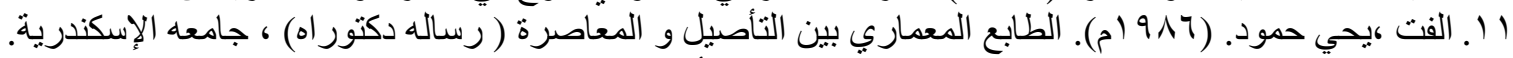

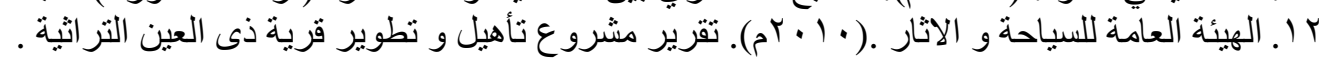

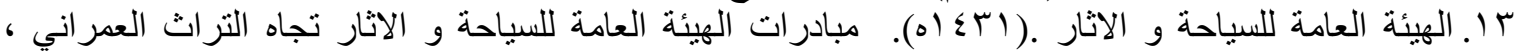

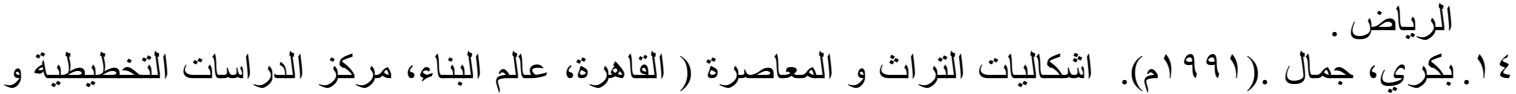

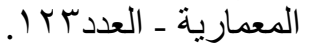

0

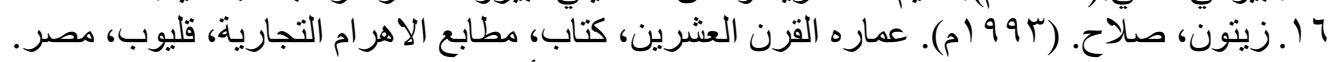

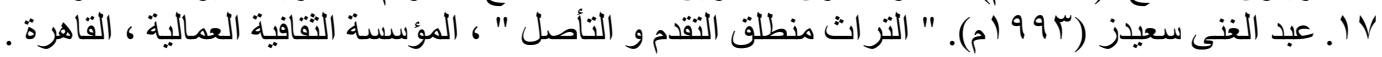

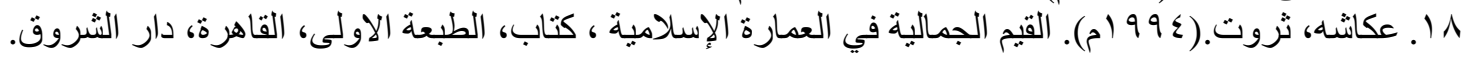

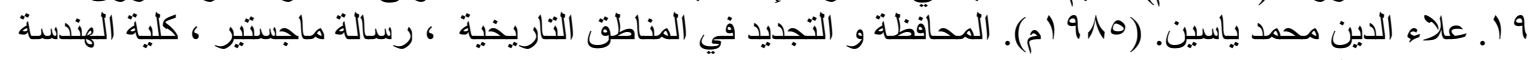

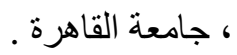

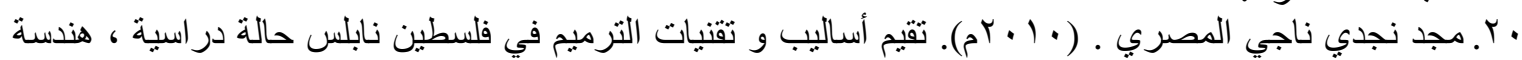

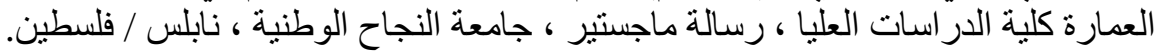

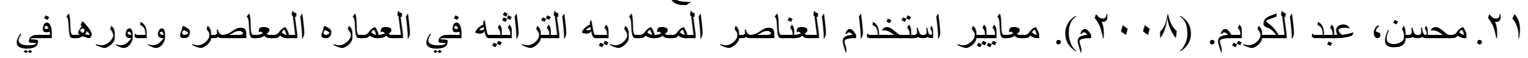

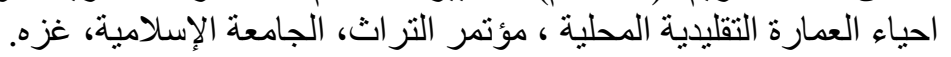

22. Ballard .C, (1976). Preservation of Man-made Resources, school of Environmental Design ,U.G.A ,Athens Georgia, U.S.A. 